\title{
Cost allocation methods in cooperative transportation planning
}

\author{
Joen Dahlberg
}

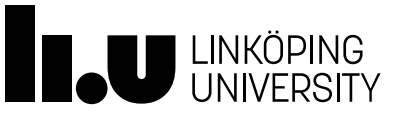

Department of Science and Technology

Linköping University, SE-601 74 Norrköping, Sweden 
Cost allocation methods in cooperative transportation planning Joen Dahlberg

Linköping Studies in Science and Technology. Dissertations, No. 1911 Copyright (C)2018 Joen Dahlberg, unless otherwise noted ISBN 978-91-7685-350-4

ISSN $0345-7524$

Linköping University

Department of Science and Technology

SE-601 74 Norrköping

Printed by LiU Tryck, Linköping, Sweden 2018 


\section{Abstract}

Transportation, together with transportation planning for goods, provides good conditions for economic growth and is a natural part of modern society. However, transportation has negative side effects, including emissions and traffic congestion. A freight forwarder may consolidate shippers' goods in order to reduce some of the negative side effects, thus reducing emissions and/or congestion as well as operational costs. The negative side effects as well as operational costs can be further reduced if a number of freight forwarders cooperate and consolidate their collective goods flows. Consolidation refers to the process of merging a number of the freight forwarders' shipments of goods into a single shipment. In this case, the freight forwarders are cooperating with competitors (the other freight forwarders).

Fair cost allocations are important for establishing and maintaining cost-efficient cooperation among competing stakeholders. Cooperative game theory defines a number of criteria for fair cost allocations and the problem associated with the decision process for allocating costs is referred to as the cost allocation problem. In this thesis, cooperative game theory is used as an academic tool to study cooperation among stakeholders in two transportation planning applications, namely 1) the distribution of goods bound for urban areas and 2) the transportation of wood between harvest areas and industries.

In transportation planning application 1 , there is a cooperation among a number of freight forwarders and a municipality. Freight forwarders' goods bound for an urban area are consolidated at a facility located just outside the urban area. In this thesis, operational costs for distributing the goods are assessed by solving vehicle routing problems. Common methods from cooperative game theory are used for allocating the operational costs among the freight forwarders and the municipality. In transportation planning application 2, forest companies cooperate in terms of the supply and transportation of common resources, or more specifically, different types of wood. Each forest company has harvest areas and industries to which the wood is transported. The resources may be bartered, that is, the forest companies may transport wood from each other's harvest areas.

In the cooperative game theory literature, the stakeholders are often treated equally in the context of transportation planning. However, there seems to be a lack of studies on cooperations where at least one stakeholder differs from the other stakeholders in some fundamen- 
tal way, for instance, as an initiator or an enabler of the cooperation. Such cooperations are considered in this thesis. The municipality and one of the forest companies are considered to be the initiators in their respective applications.

Five papers are appended to this thesis and the overall aim is to contribute to the research into cooperative transportation planning by using concepts from cooperative game theory to develop methods for allocating costs among cooperating stakeholders. The purpose of this thesis is to provide decision support for planners in the decisionmaking process of transportation planning to establish cost-efficient and stable cooperations.

Some of the main outcomes of this thesis are viable and practical methods that could be used in real-life situations to allocate costs among cooperating stakeholders, as well as support for decisionmakers who are concerned with transportation planning. This is done by demonstrating the potential of cooperation, such as cost reduction, and by suggesting how costs can be allocated fairly in the transportation planning applications considered. Lastly, a contribution to cooperative game theory is provided; the introduction of a development of the equal profit method for allocating costs. The proposed version is the equal profit method with lexicography, which, in contrast to the former, guarantees to yield at most one solution to any cost allocation problem. Lexicography is used to rank potential cost allocations and the unambiguously best cost allocation is chosen. 


\section{Populärvetenskaplig sammanfattning}

Kostnadseffektivitet och miljömedvetenhet är viktiga aspekter för en konkurrenskraftig företagsverksamhet. Dessa aspekter kan uppnås på många olika sätt och hur detta görs beror på vilken typ av företagsverksamhet som bedrivs. I denna avhandling studeras kostnadseffektivitet och miljömedvetenhet i kontexten av planering av godstransporter. I dagens samhälle är transport av gods och varor en nödvändighet. Varor produceras på ett ställe och konsumeras på ett annat. Exempelvis behöver invånarna i en stad kunna handla varor i olika butiker, såsom mataffärer och klädesbutiker. Men att lagerhålla varor är dyrt och vissa varor kan inte produceras i städer; således produceras varorna någon annanstans.

Ett sätt att uppnå kostnadseffektiva transporter är att konsolidera gods, dvs. att samlasta så mycket gods som möjligt för att fylla lastbilar eller någon typ av lastbärare i så stor utsträckning som möjligt. Då minskas antalet transporter, vilket förhoppningsvis leder till minskade transportkostnader. Ofta konsoliderar transportföretag sitt eget flöde av gods, men kostnadseffektiviteten kan öka ännu mer om flera transportföretag samarbetar och konsoliderar den total godsmängden. Då uppstår ett samarbete mellan konkurrerande transportföretag.

Ett samarbete mellan transportföretag där såväl transportplaneringen som transportutförandet är gemensamt, uppstår gemensamma kostnader. En naturlig fråga är då: "Hur ska dessa gemensamma kostnader fördelas rättvist och på ett sådant sätt att samtliga samarbetspartners är nöjda?" Syftet med en rättvis kostnadsdelning är att undvika risken att något transportföretag anser sig missgynnad och således bryter samarbetet.

Det är kostnadsdelningsfrågan som behandlas i denna avhandling, med fokus på att ge goda förutsättningar för att etablera kostnadseffektiva samarbeten. Detta görs i två typer av tillämpningsområden. Det ena tillämpningsområdet är godstransporter i urbana områden. Här antas kommunen ha en aktiv roll i samarbetet som ansvarig för flertalet ickemonetära aspekter så som minskad trängsel, ökad trafiksäkerhet och bra luftkvalité. Det andra tillämpningsområdet är hämtat från skogsindustrin, där timmer och träflis ska transporteras från avverkningsplatser till t.ex. sågverk, pappersmassaindustrier och förbränningsstationer.

De primära vetenskapliga bidragen i denna avhandling är utvecklingen av nya metoder för kostnadsdelning inom kooperativ trans- 
portplanering. Innan ett kostnadsdelningsproblem kan lösas måste kostnaden för varje delmängd av transportföretag beräknas. Detta är en förutsättning för att kunna använda såväl etablerade metoder från kooperativ spelteori som de metoder som utvecklas i denna avhandling. Kostnaderna beräknas genom att lösa ett antal transportplaneringsproblem med hjälp av optimeringsmetoder. På en mer modellmässig och beräknings-teknisk nivå handlar det vetenskapliga bidraget om hur man för varje ny tillämpning och nytt scenario anpassar, nyutvecklar och knyter samman metoderna som används. Till sist ges ett bidrag till kooperativ spelteori. Det presenteras en vidareutveckling av den existerande kostnadsdelningsmetoden equal profit method. Vidareutvecklingen medför att en unik kostnadsdelning hittas, vilket inte equal profit method garanterar. Detta görs med hjälp av lexikografi där potentiella kostnadsdelningar rangordnas och den entydigt bästa kostnadsdelningen väljs. 


\section{Acknowledgments}

The research included in this thesis was carried out at the division of Communication and Transport Systems (KTS), at the Department of Science and Technology (ITN) at Linköping University (LiU). The research has been financed by the Swedish Energy Agency (Energimyndigheten) and Sweden's Innovation Agency (Vinnova).

I would like thank my three supervisors, Stefan Engevall, Maud Göthe-Lundgren and Jenny Karlsson, who have had to put up with the task to supervise me. It is a task that has been, without a doubt, filled with turmoil and enjoyment; struggle and excitement; ups and downs. Many interesting discussions have taken place, and from time to time we have agreed to disagree. I am grateful to have had such friendly, pleasant and helpful supervisors. I would also like to thank the colleagues who have read and provided feedback on early drafts of this thesis and the papers included; an extra thanks here to NilsHassan Quttineh.

I am lucky to have had time for activities more than writing this thesis. One of the most enjoyable and stimulating of these activities is the open problem sessions. Thank you Christiane Schmidt for initiating these and taking the main responsibility for their continuation. Discussions during the open problem sessions have lead to contributions to a couple of conferences, and I am grateful to have had the opportunity to be a part of these contributions, even though air traffic management is far from my own research area. I would also like to thank the rest of my colleagues at KTS for work-related discussions, support, bolstering, joint suffering and social interactions; necessities for surviving in the harsh environment of academia.

There is one group of people who have meant a lot to me during my time in Norrköping; my beloved choir. They have made a tremendous contribution to my quality of life, and an eventual leave will be extremely difficult.

Lastly, I would like to thank my friends and family, and a special thanks to my biggest supporter and most important person, my dear mother Karin.

Kymmendö, July 2018

Joen Dahlberg 

"The struggle itself toward the heights is enough to fill a man's heart. One must imagine Sisyphus happy."

- from The Myth of Sisyphus by Albert Camus. 



\section{Contents}

$\begin{array}{ll}\text { Abstract } & \text { iii }\end{array}$

Populärvetenskaplig sammanfattning V

Acknowledgments vii

1 Introduction 1

1.1 Background 1

1.2 Motivation 3

$\begin{array}{ll}1.3 \text { Aim, overview and contributions } & 6\end{array}$

$\begin{array}{lll}1.4 & \text { Outline } & 7\end{array}$

2 Cooperative transportation planning 9

2.1 Consolidation 10

2.2 Two types of applications considered 12

2.2.1 Urban goods distribution 12

2.2.2 The forest industry 14

3 Network flow problems and vehicle routing problems $\quad 17$

3.1 Network flow problems 18

3.2 Vehicle routing problems 19

3.3 Solution methods $\quad 21$

4 Cooperative game theory 25

4.1 Cost allocation methods 26

4.1.1 Solution properties $\quad 27$

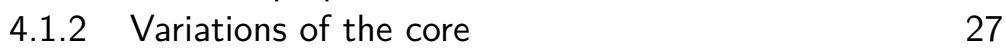

4.1.3 Common cost allocation methods 30

4.2 Examples of applications 33 
5 Summary of the papers $\quad 37$

5.1 Summary of Paper I 37

5.2 Summary of Paper II 39

5.3 Summary of Paper III 40

5.4 Summary of Paper IV 42

5.5 Summary of Paper V 44

6 Conclusions and future research 47

6.1 Short summary 47

6.2 Conclusions 48

6.3 Future research 49

Bibliography

$\begin{array}{ll}\text { Abbreviations } & 59\end{array}$

I Consolidation in urban freight transportation - Cost allocation models 61

II A note on the nonuniqueness of the equal profit method 93

III Incitements for transportation collaboration by cost allocation107

IV Consolidation in urban goods distribution - Cost allocation based on approximate solutions

$\mathrm{V}$ Using road tolls and cost allocation to improve consolidation in urban goods distribution 


\section{Chapter 1}

\section{Introduction}

Transportation, together with transportation planning for goods, provides good conditions for economic growth and is a natural part of modern society. However, transportation has negative side effects including emissions and traffic congestion. Different types of goods require different types infrastructure and transportation planning.

Five papers are appended to this thesis and two types of transportation planning applications are considered, namely

1) the distribution of goods bound for urban areas and

2) the transportation of wood between harvest areas and industries.

\subsection{Background}

Sustainability $^{1}$ is an important and well-used concept in discussions on societal development and logistics. There are several dimensions of sustainability, of which the three most common are economic sustainability, environmental sustainability and social sustainability. The three dimensions are all important for prosperity at the global level. However, a trade-off between the dimensions is commonly needed, and decision-makers are usually not equally concerned with all of these dimensions.

\footnotetext{
${ }^{1}$ See for instance the Brundtland report (1987) "Our common future", http://www.un-documents.net/our-common-future.pdf (October 2018).
} 
Arguably, the current state of freight transportation is not sustainable. For instance, Cristea et al. (2013) claim that, on average, there has been a steady growth in $\mathrm{CO}_{2}$ emission caused by international trade and international transportation, and Boden et al. (2017) report a steady growth in the annual global fossil-fuel carbon emissions, to which transportation contributes. Further, Trafikanalys (Östlund and Myhr, 2015) report a growth in both freight and personal transportation in Sweden. The need for change is evident, as reflected by global initiatives such as the Paris Agreement. ${ }^{2}$ Thus, there is a need for research regarding transportation and transportation planning. The topic of this thesis concerns cooperative transportation planning, and although sustainability is not the focus of this thesis, the topic relates to sustainability, in the sense that the methods and ideas presented may lead to more environmental and economically efficient situations.

A large part of the world's freight transportation is carried out by freight forwarders and it is common practice for a single freight forwarder to consolidate shippers' goods. As formulated by Stadtler et al. (2015, p. 226); "A particularly effective consolidation of small shipments is achieved by a Logistics Service Provider (LSP), who can combine the transports from many senders." Efficiency could improve further if multiple freight forwarders consolidate shippers' goods jointly. In such cases, there is some sort of cooperation among the freight forwarders and a common total cost is generated.

In order to maintain a cooperation, fair cost allocations are a crucial part of a business model, as pointed out by a number of researchers such as Browne et al. (2007), Cherrett et al. (2009), and Taniguchi (2014). Browne et al. (2007, p. 53) state that “... a critical element in determining the viability of an urban consolidation center scheme is the way in which the costs and benefits can be allocated between the parties involved". The problem associated with the decision process for allocating cost is referred to as the cost allocation problem.

In this thesis, cost allocation problems are solved using methods from cooperative game theory. In cooperative game theory, a number of criteria for fair cost allocations are defined. Game theory (cooperative and noncooperative) is the study of strategic decision-making and relates to mathematical economics. Furthermore, in this thesis cooperative game theory is used as an academic tool to study the

\footnotetext{
${ }^{2}$ https://treaties.un.org/pages/ViewDetails.aspx?src $=$ TREATY\&mtdsg_no $=$ XXVII-7-d\&chapter $=27 \&$ clang $=$ _en $($ October 2018).
} 
cooperation between stakeholders in two transportation planning applications.

In transportation planning application 1 , it is considered that the municipality undertakes a specific role as the enabler and initiator of the cooperation among the freight forwarders responsible for the goods distribution in an urban area. The municipality is assumed to have the opportunity to either offer subsidies to enable the cooperation or to use road tolls to motivate the freight forwarders to participate in the cooperation. The subsidies and road toll costs are incorporated in the cost allocation problem.

In transportation planning application 2, a different perspective of cooperation is studied, namely the process of establishing a cooperation in which the stakeholders, in this case forest companies, join the cooperation sequentially, and the order in which the stakeholders join is stochastic. Each time a new stakeholder considers joining the cooperation, a new cost allocation is calculated. Whether or not a stakeholder will, or will be allowed to, join the cooperation is based on the new cost allocation.

\subsection{Motivation}

Cooperation enables improvements in logistics operations and in supply chains. The fundamental idea is simple; more quantity implies more synergy, and thus, it is possible to be more efficient. Cruijssen et al. (2005, p. 2) formulate this as “...the LSP's larger economies of scale that enable him to perform transportation and warehousing more efficiently than his customers." But as Guajardo and Rönnqvist (2015) point out, there are challenges as well. For instance, when the number of stakeholders in the cooperation increases, the required coordination increases. At the same time, communication between the stakeholders becomes increasingly difficult, which makes good coordination more difficult to accomplish. Guajardo and Rönnqvist (2015) study the issue of maintaining large cooperations in logistics activities and develop optimization models which enables the formation of a number of smaller stable cooperations rather than one large cooperation. In this context, stable means that there are no economic incentives for any subset of stakeholders to leave the cooperation and thus act without the others.

Cooperation among competitors is sometimes called coopetition 
or horizontal cooperation. Bengtsson and Kock (2000) study the importance of coopetition from both perspectives; competition and cooperation. They argue that these two perspectives are not mutually exclusive.

A number of researchers such as Eriksson et al. (2006), Teo et al. (2012), and Wangapisit et al. (2014) conclude that cooperative transportation planning can lead to a reduction of emissions and congestion. Not only will the environmental and societal impacts be reduced, but the operational costs (e.g., fuel and labor) might also be reduced. Lozano et al. (2013) study the case where four shippers are using a common LSP and cost reductions are realized by merging the shippers' transportation needs. Lozano et al. (2013) solve the cost (savings) allocation problem and test different methods from cooperative game theory on a numerical example. Based on the transportation costs in Lozano et al. (2013), it can be calculated that the cost reduction for the cooperation is $32 \%$. Further, Frisk et al. (2010) consider a case from the forest industry and estimate a cost reduction of $8-9 \%$ resulting from a cooperation among eight forest companies transporting wood in Sweden.

If a cooperation among stakeholders is considered and the logistics operations are optimized at a system level, then the logistics operations may be detrimental for some stakeholders. Moreover, a cost allocation problem arises due to the cooperation. A common approach to solve cost allocation problems is to formulate them as cooperative games and calculate optimal costs or profits. By providing cost allocations which are beneficial to all stakeholders, cooperative game theory can be used as a tool to encourage system optimal solutions.

Cooperative game theory and cost allocation problems have been used in the literature in the context of cooperative transportation planning. For instance, Özener and Ergun (2008) study how costs associated with a transportation network can be allocated among shippers. Shippers cooperate, and the cost of covering all demand in the network is optimized by consolidating the shipments, thus enabling negotiation of better rates with a common carrier. The goal of their paper is to develop cost allocation methods that "ensure sustainability of the collaboration". The shippers are those who initiate and coordinate the cooperation. However, the relationship between shippers and the carrier can be reversed, as shown by Cruijssen et al. (2005). They study a case in which an LSP successively invites shippers with strong synergy potentials to cooperate, by means of cost saving offers. 
Cruijssen et al. (2005) denote the process of successive invitation as "insinking" and describe it as the antonym of outsourcing. In this context, outsourcing refers to the process in which a company transfers or contracts out some of its activities to another company. The ideas presented in Cruijssen et al. (2005) are adopted in Paper III; however, a simultaneous invitation is considered in Paper III instead of a successive invitation.

Transportation planning application 1, considered in this thesis (Papers I, IV and V), concerns urban goods distribution. In this context, Yang and Odani (2007) study a cost allocation problem which arises when a number of logistics companies use a consolidation center in order to improve the goods distribution. Yang and Odani (2007) simultaneously allocate operational costs and fixed costs among the cooperating logistics companies. In their paper, the fixed costs include the cost for constructing the consolidation center and the investment cost for vehicles, whereas in this thesis, only operational costs are considered. Yang and Odani (2007) consider only logistics companies as stakeholders, but they point out that a cooperation among the companies should be established by either a central company or with the assistance of the municipality. The latter case is studied in this thesis and the municipality is included as an enabler of the cooperation. With regards to future research, Yang and Odani (2007) mention the use of subsidies (discussed in Paper I) and the use of realistic cases (Papers IV and V). Further, because of the difficulties of solving certain real-life transportation planning problems to optimality (for the purpose of calculating optimal costs or profits), in Papers IV and V calculating approximate costs instead of optimal costs is suggested.

Flexibility is a key aspect for generating synergy effects among cooperating stakeholders, and Vanovermeire and Sörensen (2014) argue that stakeholders with large flexibilities, for instance in terms of delivery dates and order sizes, should be rewarded. However, in the case of two-partner coalitions, flexibility is not usually rewarded when cooperative game theory is used. Thus, they propose an alternative approach to allocating costs. This approach considers two scenarios for each cooperating stakeholder: the stakeholders may or may not be flexible. This approach is beyond the scope of this thesis, but it is somewhat similar to an aspect discussed in Paper III, where both constructive and destructive characteristics are considered. The approach used by Vanovermeire and Sörensen (2014) is also similar to the phenomena of cooperative potential and bargaining potential 
which are well studied in the literature of cooperative game theory. For instance, Sudhölter (1996) proposes a profit allocation method that takes into account both the cooperative potential and bargaining potential of all possible coalitions among the stakeholders.

In the literature of cooperative game theory, the stakeholders are often treated equally. However, there seems to be a lack of studies on cooperations where at least one stakeholder differs in some way from the other stakeholders. Such cooperations are studied in this thesis. Each of the papers appended with the exception of Paper II, includes an initiator, or enabler, of the cooperation, that is, a dominant player or stakeholder.

To summarize, some of the research gaps that are addressed in this thesis include: analysis of the effects on cost allocations based on approximate costs instead of optimal costs; the inclusion of a dominant player in the cost allocation problem, especially the inclusion of the municipality in the context of goods distribution in urban areas; and a case when stakeholders join the cooperation sequentially and the order is stochastic.

\subsection{Aim, overview and contributions}

The overall aim of this thesis is to contribute to the research in cooperative transportation planning by using concepts from cooperative game theory, and to develop methods for allocating costs among cooperating stakeholders. The purpose is to provide models and methods which can be used to support the decision-making process of transportation planning to establish cost-efficient and stable cooperations. This is done by demonstrating the potential of cooperation and by suggesting how costs can be allocated fairly in different transportation planning applications.

Formulating and solving optimization problems are essential elements of this thesis. All the problems concerning transportation planning, as well as the majority of the cost allocation problems in Papers I-V, are modeled as optimization problems.

Some of the main contributions of this thesis are viable and practical methods that could be used in real-life situations to allocate costs among cooperating stakeholders. The contributions of each paper are as follows.

I) A conceptual framework in which freight forwarders and the 
municipality may cooperate with regards to urban goods distribution and share the total operational costs. Additional contributions are the analyses of how the total operational cost might be allocated fairly among the stakeholders, as well as suggestions as to how additional side costs generated as a result of cooperating can be handled.

II) A development of the Equal Profit Method (EPM) for allocating costs. The proposed version is the Equal Profit Method with Lexicography (EPML), which, in contrast to the former method, guarantees to yield at most one solution to any cost allocation problem.

III) A framework to establish a cooperation among stakeholders when the stakeholders join the cooperation sequentially and the order in which they join is stochastic. The cooperation is motivated by using the cost allocation mechanisms that are developed in the paper to make fair cost allocations. The cost allocation mechanisms are additional contributions.

IV) A viable and practical method that could be used in real-life situations to allocate costs among cooperating stakeholders responsible for the distribution of goods in an urban area. In this context, viable and practical means that the method has acceptable computational times and produces reasonable numerical results, even for real-life-sized problems corresponding to a medium-sized city in Sweden.

V) A further development of the models and methods developed in Papers I and IV which includes road tolls and alternative vehicle fleets.

The applicability of the methods in Papers IV and V are verified and discussed by using real-life cases of urban goods distribution in the cities of Linköping and Norrköping, respectively. Both cities are medium-sized cities in Sweden with approximately 140,000 inhabitants.

\subsection{Outline}

Chapter 2 presents a short overview of cooperative transportation planning. This is the common theme of the papers in this thesis. 
In Section 2.2, the two types of transportation planning applications considered in this thesis are described. One of the applications concerns the distribution of goods bound for urban areas and the other application concerns transportation of wood between harvest areas and industries, that is, the application is a part of the forest industry.

Formulating and solving optimization problems are essential elements of this thesis and a number of optimization problems and solution methods, that are related to this are presented in Chapter 3. Optimization is used to solve transportation planning problems and cost allocation problems.

Cooperative game theory - the academic tool used in this thesis - is thoroughly explained in Chapter 4 . The chapter is mainly theoretical, but ends with a variety of applications where cooperative game theory has been used.

Papers I-V are summarized in Chapter 5, and some conclusions and suggestions for future research are presented in Chapter 6 . 


\section{Chapter 2}

\section{Cooperative transportation planning}

The purpose of this chapter is to give a brief overview of cooperative transportation planning and the applications considered in this thesis.

Cooperative, or at least coordinated, transportation planning may occur when different types of goods are bound for the same customer or bound for different customers in the same geographic area, for instance, the distribution of goods to urban areas via a jointdelivery-system (Taniguchi, 2014). Such a system is established in Lucca, a medium-sized Italian city with a historic city center from the 16th century. According to Ambrosino et al. (2007), local authorities have taken a number of means, such as introducing regulations and mobility schemes in order to preserve the quality of tourist assets (attracting tourists) as well as improving the local environment. A consolidation center is located just outside the city center, providing opportunities to sort and transit goods to new routes, using small and environmentally friendly vehicles.

Stakeholders, workplaces or establishments in a region have the opportunity to cooperate and coordinate their inbound or outbound flows of goods. Moen (2014) and Björklund and Gustafsson (2015) report that some municipalities in Sweden have started to coordinate their daily goods distribution to destinations such as schools, offices and retirement homes, and Cherrett et al. (2009) are studying a system in Winchester, where local shops have invested in a coordinated 
waste disposal system.

Coordination may also occur when there are transportation needs in two directions in the same system; this is called backhauling. In the transportation planning problem presented by Bailey et al. (2011), sodas are transported in crates which are left at the customer's, and crates filled with empty bottles are sent back. Bailey et al. (2011) develop mixed integer optimization models for cooperation among freight forwarders in the context of backhauling, and Ropke and Pisinger (2006) develop mathematical methods and models for a large class of problems with backhauling.

Stakeholders who share a common type of resource can reduce transportation costs through synergy effects when the resource is bartered. They cooperate in terms of supply sharing. Forsberg et al. (2005) provide examples of the bartering of wood to reduce transportation costs in the forest industry. They also include backhauling trips which reduce the transportation costs further.

A Vendor Managed Inventory (VMI) is an example in which cooperation occurs among different types of stakeholders with similar interests. In a VMI setting, the general idea is that a supplier is responsible for managing the inventory of their own customers. In exchange for this additional work, the supplier receives useful information which results in better planning possibilities. Li et al. (2015b) use cooperative game theory to achieve a stable VMI cooperation between a company and a number of retailers.

\subsection{Consolidation}

In order to reduce the number of vehicles needed in transportation, goods can be consolidated and sent as larger bulks. In this context, consolidation refers to the merging of a number of shipments of goods into a single shipment. The consolidation of goods can for instance occur in multimodal transportation, in which several modes of transportation are used. An example of a multimodal transportation case is found in the work of Diziain et al. (2012), who consider the utilization of waterways and railways for urban goods distribution. The transitions between the modes require a suitable infrastructure and locations that enable the modal change. Consolidation is not exclusive to multimodal transportation. For example, in a transportation system using only one mode of transportation, the goods in two half 
full vehicles can be consolidated into one full vehicle. Although in some circumstances it is efficient to consolidate, each transition induces additional costs and time. These additional costs might exceed the gains of consolidation and delivery lead time might increase due to the additional time spent on the transition.

In the context of urban goods distribution, establishing a consolidation center provides opportunities to invest in new vehicles and vehicle fleets. In Paper V, two types of homogeneous vehicle fleets are considered. Duin et al. (2013) study the possibilities of using different fleets of electric trucks and a consolidation center in Amsterdam from an economic perspective. The distribution of goods from the consolidation center to the city center is modelled as Vehicle Routing Problems (VRPs) with constraints related to vehicle battery capacities. They estimate the costs for distributing goods based on the different fleet compositions, by solving the VRPs. The costs and routing solutions are compared and analyzed. Navarro et al. (2016) present energy-efficient solutions for urban goods distribution in six Mediterranean cities. They report on the results from pilot tests that use electric tricycles and consolidation centers. Schliwa et al. (2015) investigate the possibility of using cargo cycles for urban goods transportation in the UK and Browne et al. (2011) report on the results of a pilot study in which electric vans and tricycles operate from a micro-consolidation center in the City of London. Browne et al. (2011) conclude that the $\mathrm{CO}_{2}$ emissions are reduced significantly and that the total distance travelled increases substantially, compared to when diesel vans are used. Neither tricycles nor cargo cycles are considered in this thesis; the only mode of transportation is by truck.

In Papers I, IV and V, the location of a consolidation center is provided and in the case of a demonstration project (Eriksson et al., 2006; Eriksson and Svensson, 2008), an already existing facility was utilized as a consolidation center because establishing new facilities is associated with high initial costs. However, in some cases, no available facilities may exist and a consolidation center needs to be established. When deciding on the strategic placement of consolidation centers, the location problem can be modeled with different layers or echelons of supply chains. Such model is typically used when one or a few major consolidation centers as well as smaller local delivery stations are to be located. The major consolidation centers constitute one echelon and the small delivery stations constitute another echelon. Tragantalerngsak et al. (2000) develop a mixed integer optimization 
model and a solution method ${ }^{1}$ to solve the two-echelon facility location problem. The focus of their paper is on the methodology and the test problems are general, that is to say that no particular application is studied. Based on the performance of solving the test problems, they claim that the solution method is efficient.

In some cases, such as in Papers I, IV and V, the locations of consolidation centers are given. Crainic et al. (2009) study a problem in which the locations of consolidation centers are given, and they present a model for solving a day-before problem, a problem type where the demands for the next day are known. The distribution of goods is planned in an urban goods distribution context with a number of consolidation centers. The new problem is called the two-echelon, synchronized, scheduled, multidepot, multiple-tour, heterogeneous vehicle routing problem with time windows.

\subsection{Two types of applications considered}

In this thesis, two types of transportation planning applications are considered, as was briefly described in Section 1.1. More detailed descriptions of these applications are provided below.

\subsubsection{Urban goods distribution}

Due to the typical characteristics of an urban area, transportation planning is different compared to that in a regional, national or international context. Aspects which are exclusive to the urban area must be taken into account. In an urban area, the streets are narrower, the traffic is denser and unoccupied parking spaces are sparse. The delivery points are geographically closer to each other and there are more stops, which results in more frequent parking. The ratio between the time spent handling goods and the time spent driving is much larger for urban areas than for long distance transportation. During a demonstration project (Eriksson et al., 2006; Eriksson and Svensson, 2008) in Linköping, regarding urban goods distribution, the amount of time spent handling goods was almost six times more than the time spent driving. Further, Allen et al. (2018) conducted a case study of e-commercial parcel deliveries in the central London. They report that the amount of time spent handling goods was on

\footnotetext{
${ }^{1} \mathrm{~A}$ Langrangian relaxation-based branch and bound algorithm.
} 
average $62 \%$ of the total time spent on the deliveries, with a peak of $77 \%$, which corresponds to a ratio of $1.6-3.3$ between the time spent handling goods and the time spent driving. It is not surprising that the ratio is lower in the London case because parcels are smaller and easier to handle than the goods delivered during the demonstration project in Linköping.

In the context of the cooperative transportation planning of urban goods distribution, Taniguchi (2014) claims that it is common to include a City Distribution Center (CDC) as one means of improving certain aspects in urban areas. The use of a CDC can make urban goods distribution more efficient by consolidating goods and thus, improve traffic conditions by reducing the number of vehicles, especially large trucks; and possibly improve the quality of life by using environmentally friendly vehicles. A CDC is included in Papers I, IV and V. Björklund and Gustafsson (2015) and Taniguchi (2014) claim that an appropriate location for the CDC is near the urban area, and thus, being accessed from a main road and not too far from the urban area. If the CDC is located in the middle of the urban area, then large trucks need to travel into the urban area, which is counter-productive with respect to the aim of reducing the number of large trucks in the urban area.

Urban goods distribution and the use of CDCs are elements of City Logistics (CL) and Allen et al. (2007) provide an extensive guide to the topic. CL can be summarized as follows: There are several types of stakeholders, both external and internal, who are affected by CL (e.g., transportation companies, goods receivers/owners, real estate owners, visitors, inhabitants and the municipality). They have diverse objectives and they value different impacts differently. The impacts include economic impacts (e.g., travel time and resource use), environmental impacts (e.g., pollutant emissions and $\mathrm{CO}_{2}$ emissions) and social impacts (e.g., risk for injuries, public health and quality of life). There are several CL means, but due to the stakeholders' diverse objectives, the means are often beneficial for some stakeholders and detrimental to others. The means range from those that are infrastructural or policy-based to logistical or technological. Taniguchi et al. (1999) and Taniguchi et al. (2001, p. 13) define CL as "the process for totally optimizing the logistics and transport activities by private companies in urban areas while considering the traffic environment, the traffic congestion and energy consumption within the framework of a market economy". The means considered in this thesis are mainly 
logistical, or more specifically, concerned with cooperative transportation planning.

The transportation planning problems considered in Papers I, IV and $\mathrm{V}$ involve a number of freight forwarders operating in an urban area. There are delivery points in the urban area, and each delivery point corresponds to a customer. Customers may receive deliveries from multiple freight forwarders. As a representative of different external stakeholders such as inhabitants and tourists, the municipality is interested in reducing the negative social and environmental impact of the freight forwarders' operations. Therefore, the municipality suggests that the freight forwarders cooperate and use a CDC instead of operating individually, independently of each other. By cooperating, both the number of vehicles used and the number of visits to customers can be reduced. Instead of receiving multiple deliveries, each customer receives only one delivery, via the CDC. By cooperating, the total distance travelled and the total time spent on delivering the goods can be reduced as well. The municipality is assumed to take a specific role as the initiator, or enabler of a cooperation among freight forwarders with goods bound for the urban area.

The municipality or local authorities have an important or even crucial role in the context of urban goods distribution, as pointed out by several researchers (e.g., Björklund and Gustafsson, 2015; Browne et al., 2007; Schliwa et al., 2015; Taniguchi, 2014; Yang and Odani, 2007). The municipality is therefore included in Papers I, IV and V and its role is also discussed.

\subsubsection{The forest industry}

The forest industry involves activities such as forest management, harvesting, transportation, production and sales as described by D'Amours et al. (2008) who present a descriptive model of the wood fiber flow in the supply chain from the forest to the customer, for different forest industry products. Forest management consists of activities such as planting, pruning, fertilizing and thinning and involves strategic planning. The planning horizon is long, because it needs to follow the life cycles of the trees planted, that is, the time from plant to fully grown tree. The trees are grown in order to meet future demands, and different forest industry products require different types of wood. Harvesting is planned at a tactical level. Decisions are made regarding which areas to harvest and where to build forest roads for 
easier access. The wood is cut either into logs or chips, depending on the intended production. The wood harvested is transported by trucks, either directly to industries or to railway hubs or seaports for further transportation. Some of the items produced are sawn and profiled wood, pulp, paper, cardboard and various types of fuel; see for instance Stora Enso ${ }^{2}$ and Holmen ${ }^{3}$. Lastly, regarding sales, because of the many different items produced, there is a very broad spectrum of customers and consumers.

A mixed integer optimization model, which integrates harvesting, forest road building and material flows is developed by Andalaft et al. (2003), and only a part of the descriptive model by D'Amours et al. (2008) is taken into account. Andalaft et al. (2003) have also developed solution methods ${ }^{4}$ which improve the computation time significantly compared to simply using commercial (all-purpose) optimization solvers. The model is tested on several instances and later implemented and used by a Chilean forest company. In Paper III, a specific part of the descriptive model is considered, namely, the transportation of wood between the harvest areas and the industries.

The case considered in Paper III, as well as in Frisk et al. (2010), involves a number of forest companies operating in the southern part of Sweden, where each forest company's harvest areas and industries are located. The part of their operations that is suitable for a potential cooperation is the transportation of wood between the harvest areas and the industries. A cooperation among the forest companies can reduce the total transportation cost due to synergy effects when the wood is bartered, or more specifically, the forest companies can transport wood from each other's harvest areas. A conceptual example is shown in Figure 2.1. The black lines represent transportation of wood, small circles represent harvest areas, and large circles represent industries.

In Paper III, it is assumed that one of the forest companies, the initiator of the cooperation, invites the other forest companies to participate in the cooperation. The forest companies join the cooperation sequentially and the order in which the forest companies join is stochastic. Who will agree to cooperate is not predefined, but it is assumed that larger cooperations are preferable to smaller coopera-

\footnotetext{
${ }^{2}$ http://www.storaenso.com/ (October 2018).

${ }^{3}$ https://www.holmen.com/ (October 2018).

${ }^{4}$ Solution methods include: reducing the domain; strengthening the LPrelaxation and; Lagrangian relaxation.
} 

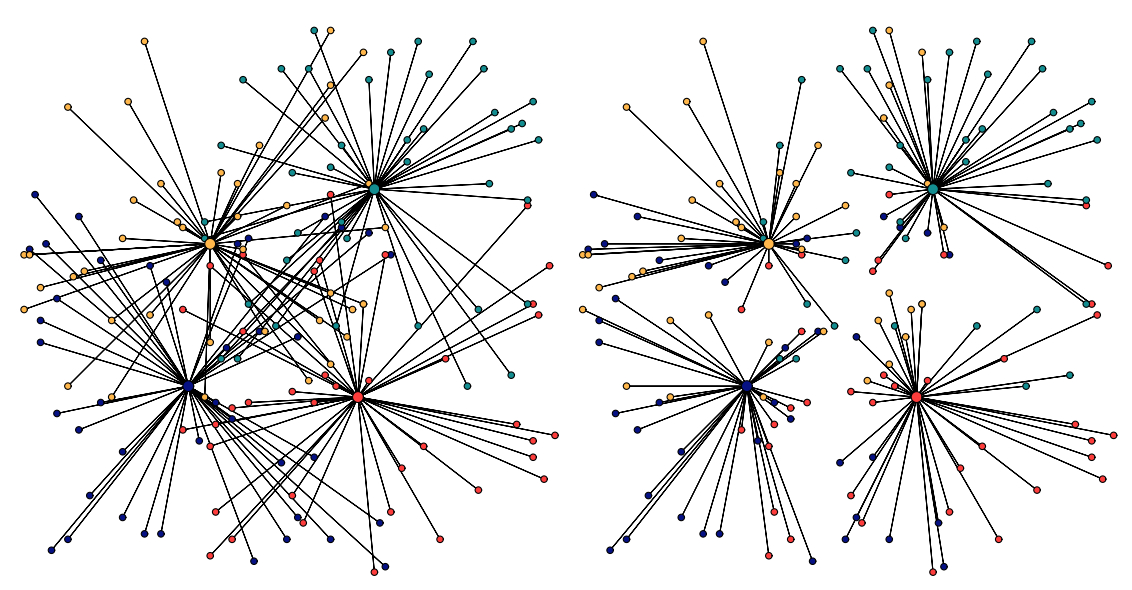

Figure 2.1: Conceptual example of the transportations without cooperation (left) and with cooperation (right), involving four forest companies (yellow, red, blue and turquoise) each with one industry and multiple harvest areas.

tions, because larger cooperations tend to be more cost efficient in the case considered. Each time a new forest company considers joining the cooperation, a new cost allocation is calculated. Whether or not a forest company will, or will be allowed to, join the cooperation is based on the new cost allocation.

Unlike the assumption made in Paper III, Frisk et al. (2010) assume that all of the forest companies will cooperate and the cost allocation problem is solved only once. In order to solve the cost allocation problem, Frisk et al. (2010) develop a method for allocating the total transportation cost, namely the Equal Profit Method (EPM); see Section 4.1.3. The method is compared with other cost allocation methods from cooperative game theory by analyzing results from a number of test instances associated with the cooperation among the forest companies. In Paper III, a number of cost allocation mechanisms are developed. 


\section{Chapter 3}

\section{Network flow problems and vehicle routing problems}

The transportation planning problems and the main part of the cost allocation problems considered in this thesis are formulated as optimization problems. The scientific contribution of this thesis is related to cooperative transportation planning and how to apply existing optimization methods in this context. That is, optimization is used as the fundamental tool to solve the problems considered and is therefore briefly described in this chapter. The transportation planning problems considered in Paper III are formulated as a version of the network flow problem (see Section 3.1) whereas different versions of the Vehicle Routing Problem (VRP) (see Section 3.2) are formulated and solved in Papers I, IV and V. Cost allocation problems and methods are described in Chapter 4 and are therefore not included in this chapter.

An optimization problem consists of a set of variables that may be represented by a vector, $\mathbf{x}^{\top}=\left(x_{1}, x_{2}, \ldots, x_{n}\right)$, an objective function, $f(\mathbf{x})$, and a set of equations and/or inequalities; that is, constraint $j$ may be represented by the equation, $g_{j}(\mathbf{x})=0$ or the inequality, $g_{j}(\mathbf{x}) \geqslant 0$. The objective is to find a vector, $\mathbf{x}^{*}$, satisfying all constraints and that either minimizes (minimization problem) or maximizes (maximization problem) the objective function, $f(\mathbf{x})$.

A real-life problem is to be solved and is modelled such that the variables correspond to decisions to be made, or to unknown values 
of the real-life problem. The constraints correspond to limitations of the real-life problem and/or relationships between the variables. The objective function values correspond to some quantifiable magnitude that is intended to be as large or as small as possible.

The two types of optimization problems considered in this thesis are described in the following sections.

\subsection{Network flow problems}

Ahuja et al. (1993) present an extensive overview of network flow problems. A basic network flow problem consists of a set, $N$, of nodes and a set, $A$, of arcs. Each arc, $(i, j)$, is associated with a pair of nodes (in case of directed graphs, the arc goes from node $i$ to node $j$ ). Each node, $i$, has a supply, $s_{i}$, which may be strictly positive (supply nodes), 0 (intermediate nodes), or strictly negative (demand nodes). Each arc may have a flow cost, $c_{i j}$, and also be associated with a lower bound, $l_{i j}$, and an upper bound, $u_{i j}$, on the flow. The aim is to send a flow from the supply nodes to the demand nodes through the network at the lowest cost, while satisfying flow bounds on the arcs.

In order to formulate the basic network flow problem, let $x_{i j}$ be a variable indicating the flow on $\operatorname{arc}(i, j)$. The positive direction is from $i$ to $j$. Let $A_{k}=\{(i, j) \in A \mid i=k\}$ and $A^{k}=\{(i, j) \in A \mid j=k\}$. Then the basic network flow problem can be expressed as the problem to

$$
\text { minimize }
$$

$$
\sum_{(i, j) \in A} c_{i j} x_{i j}
$$

subject to

$$
\begin{aligned}
x_{i j} & \geqslant l_{i j}, & (i, j) & \in A, \\
x_{i j} & \leqslant u_{i j}, & (i, j) & \in A, \\
\sum_{(i, j) \in A_{k}}\left(x_{i j}\right)-\sum_{(i, j) \in A^{k}}\left(x_{i j}\right) & =s_{k}, & k & \in N .
\end{aligned}
$$

The expression (3.1a) describes the aim to minimize the total flow cost. The constraint sets (3.1b) and (3.1c) ensure that the flow on each arc satisfies the bounds. The constraint set (3.1d) ensures that the net-flow (out-going flow minus in-coming flow) of each node is equal to the supply of the node.

The transportation planning problem considered by Frisk et al. (2010) and in Paper III, as described in Section 2.2.2, is modelled 
as a slightly different network flow problem than the basic network flow problem. The overall supply is greater than the overall demand. Thus, the constraints in (3.1d) that are associated with supply nodes are changed to inequality constraints, and state that the net-flow must be less than or equal to $s_{k}$. Furthermore, there are only supply nodes (harvest areas) and demand nodes (industries) and there are no intermediate nodes. The flows represent how much wood is sent between each pair of supply nodes and demand nodes. There is no upper bound on the flow, but there is a lower bound of 0 .

\subsection{Vehicle routing problems}

A basic Vehicle Routing Problem (VRP) (Dantzig and Ramser, 1959) consists of a set of customers, a depot and a set of vehicles. Each customer has a demand and each vehicle has a capacity. The aim is to construct a set of routes originating from and returning to the depot such that all customers are covered by a route. Each route is associated with a vehicle, and the total demand of customers covered by the route is constrained to not exceed the capacity of the vehicle. The set of routes are chosen such that the total cost or distance is minimized.

One way to model a VRP, as presented by Toth and Vigo (2014), is to model the customers and the depot as nodes and to consider the arcs between all pairs of nodes. Each vehicle's route is then represented by a selection of connected arcs. Let:

$N$ denote the set of nodes (the depot is node 0 );

$V$ denote the set of vehicles;

$b$ denote the capacity of the vehicles;

$c_{i j} \quad$ denote the cost or distance from node $i$ to node $j$;

$d_{i} \quad$ denote the demand of node $i\left(d_{0}=0\right)$;

$x_{i j k}$ be a binary variable indicating whether vehicle $k$ travels from node $i$ directly to node $j\left(x_{i j k}=1\right)$ or not $\left(x_{i j k}=0\right)$;

$y_{i k}$ be a binary variable indicating whether vehicle $k$ visits node $i$ $\left(y_{i k}=1\right)$ or not $\left(y_{i k}=0\right)$. 
Then the VRP can be expressed as the problem to

$$
\begin{array}{rr}
\operatorname{minimize} & \sum_{\substack{i, j \in N \\
k \in V}} c_{i j} x_{i j k}, \\
\text { subject to } \sum_{i \in N} d_{i} y_{i k} \leqslant b, & k \in V, \\
\sum_{k \in V} y_{i k}=1, & i \in N \backslash\{0\}, \\
\sum_{j \in N} x_{i j k}=y_{i k}, & k \in V, i \in N, i \in N, \\
\sum_{j \in N} x_{j i k}=y_{i k}, & S \subseteq N \backslash\{0\}, \\
\sum_{i \in N \backslash S} x_{i j k} \geqslant\left\lceil\sum_{i \in S} \frac{d_{i}}{b}\right], & \\
k \in V & \\
x_{i j k} \in\{0,1\}, & i \in N, j \in N, k \in V, \\
y_{i k} \in\{0,1\}, & i \in N, k \in V .
\end{array}
$$

The expression (3.2a) describes the aim to minimize the total cost or distance. The constraint set $(3.2 \mathrm{~b})$ ensures that the capacity of each vehicle, $k$, is not exceeded. The constraint set (3.2c) ensures that each node, $i$, with the exception of the depot, is visited by exactly one vehicle. The constraint sets (3.2d) and (3.2e) ensure that if any vehicle $k$ visits node $i$, then vehicle $k$ must depart from and arrive at node $i$, respectively. The constraint set (3.2f) is the set of subtour elimination constraints. In this context, a subtour is a route that is disconnected from the depot.

This type of model is similar to a network flow model and constitutes the basis of the VRPs formulated in Papers I, IV and V. However, some changes have been made in the papers, such as a reformulation of the objective function and additional constraints and variables are included. For instance, the objective function (3.2a) only considers an arc-based cost, whereas some of the costs considered in the papers are stopping costs associated with each node and correspond to the time the vehicle is parked at the node (the customer). Further, in Paper V, additional constraints are added. The constraints involve distance limitations corresponding to the range of the battery of an electric vehicle, that is, the maximum distance to travel before the battery needs recharging. 
The research on VRPs is extensive. Many versions of the VRP have been suggested and a large number of solution methods developed. A number of examples of VRP-related literature have already been discussed in previous chapters as well as in the papers appended to this thesis. Toth and Vigo (2014) list some versions of the VRP, versions such as time windows, backhauls, pickup and delivery, stochastic travel times and stochastic demand. Further, Koç et al. (2016b) identify a large number of versions of the VRP, such as heterogeneous vehicle fleet, split delivery, multi-trips, multi-depot, open routes, green routing and the use of external carriers. The versions may of course be combined.

The objective function of the VRP considered in Paper $\mathrm{V}$ is a cost function which depends on time and fuel consumption. Other versions of the VRP that consider fuel consumption are the green VRP (green routing) e.g. Çimen and Soysal (2017) and the Pollution Routing Problem (PRP) e.g. Franceschetti et al. (2017). However, in the green VRP and the PRP, the purpose of assessing the fuel consumption is to be able to minimize environmental impact such as $\mathrm{CO}_{2}$ emissions, and not to minimize costs or distance, which are traditional objectives when solving VRPs. Çimen and Soysal (2017) consider a time-dependent green VRP with stochastic travel time and develop a solution method ${ }^{1}$ and also compare the results between the cost minimization solutions and emission minimization solutions provided by their method. Franceschetti et al. (2017) develop a solution method $^{2}$ to solve PRPs and conduct an extensive test regarding solution quality and computational time. The test includes medium to large sized PRPs with up to 200 customers.

\subsection{Solution methods}

Solution methods are used to find solutions to mathematical problems and models, and thus, also to optimization problems and models. Bertsimas and Tsitsiklis (1997) describe some exact methods such as the simplex method, binary search methods and various decomposition methods. Exact methods guarantee global optimal solutions.

\footnotetext{
${ }^{1}$ The solution method is an approximate dynamic programming based heuristic originating from machine learning and neural networks.

${ }^{2}$ An adaptive large neighbourhood search heuristic involving several operators for generating a feasible initial solution and neighbouring solutions as well as a possibility for parameter tuning affecting the solution method.
} 
However, the computer memory and computational time required might be too much and/or too long ${ }^{3}$ for exact methods to be viable in practice. This is especially the case for many mixed integer optimization problems closely related to this thesis, and the critical issue is often the integrality constraints. Other possible issues when solving optimization problems to optimality might include extensive numbers of variables and/or constraints; however such issues are not exclusive to mixed integer optimization problems. In cases when exact methods are not practical or not even feasible to use, Talbi (2009) and many before him suggests using heuristic methods instead. Heuristic methods are solution methods that hopefully find good solutions in reasonable computational time using limited computational power with regards to both CPU and memory. However, there is no guarantee that a global optimal solution will be found when using heuristics.

Issues occur when solving the optimization problem (3.2) for large problems. The main issue is that the cardinality of the constraint set (3.2f) increases exponentially relative to the number of nodes. In Paper I, the optimal solutions to VRPs are computed a priori using constraint generation. This is done by solving subproblems, defined by $(3.2 \mathrm{a})-(3.2 \mathrm{e}),(3.2 \mathrm{~g}),(3.2 \mathrm{~h})$ and a subset of the subtour elimination constraints in (3.2f). If an optimal solution to a subproblem is not feasible in the main problem (3.2), that is, subtours are identified, then the subtour elimination constraints associated with the identified subtours are added to the subproblem and a new optimal solution is computed by solving the new subproblem. This is repeated until an optimal solution to the subproblem is feasible in the main problem. Constraint generation is related to column generation (e.g., Gilmore and Gomory, 1961) and has been used in the literature, for instance by: Crowder and Padberg (1980) for solving large-scale travelling salesman problems; Göthe-Lundgren et al. (1996) for solving cost allocation problems; Mahmoudzadeh et al. (2016) for solving optimization problems related to radiation therapy; Della Croce et al. (2017) for solving job shop problems; Mrad and Hidri (2015) when minimizing electric usage for vehicle trips in a transportation system.

In Papers IV and V, a method similar to constraint generation is used to solve VRPs and involves including lazy constraints in the model. The possibility to use lazy constraints is a feature included

\footnotetext{
${ }^{3} \mathrm{~A}$ computer can run out of memory and it is limited in terms of computational operations per second, thus affects computational time. Time is a limiting factor in practice and the computational time may surpass the real-life time available.
} 
in many commercial solvers such as Gurobi Optimization (2016). In this context, a commercial solver is a software designed to solve general optimization problems expressed by variables, constraints and an objective function.

The major differences between the method of including lazy constraints and the constraint generation method involves how often subtours are identified and corresponding subtour elimination constraints are added, as well as how the new constraints are used in the subproblems. In the constraint generation method used in Paper I, the subproblems are solved to optimality at which point the subtour elimination constraints associated with the identified subtours are added to the subproblem. However, if lazy constraints are used, subtours are identified as soon as a feasible solution to the subproblem is found, and the corresponding subtour elimination constraints are added to a pool of lazy constraints. The commercial solver decides which of the lazy constraints to add to the subproblem and also whether or not some of the already added lazy constraints should be removed. The process of adding and removing lazy constraints occurs frequently throughout the solving process.

When using a commercial solver, it is possible to set a termination criterion, and when the termination criterion is satisfied, the commercial solver terminates and returns the best found feasible solution. However, there is no guarantee that the solution is optimal and it is not even guaranteed that any feasible solution will be found. Using a commercial solver with a termination criterion is in a sense a heuristic method or approach, because optimality is not guaranteed. In Papers IV and V, a termination criterion is used and an initial feasible solution is provided in order to guarantee that at least one feasible solution is found when the commercial solver terminates. In both papers, the initial solution is found using the heuristic method Clarke and Wright algorithm (Clarke and Wright, 1964). In Papers IV and $\mathrm{V}$, the choice of heuristic method is not crucial, and therefore a fast and easy-to-implement heuristic was chosen.

Conceptually the Clarke and Wright algorithm begins with one route for each customer $i$ (see Figure 3.1) and the cost of each route is $c_{0 i}+c_{i 0}$ where $c_{i j}$ is the cost or distance from node $i$ to node $j$ and node 0 is the depot. Incremental savings (cost reductions), $s_{i j}$, for merging routes are calculated as $s_{i j}=c_{i 0}+c_{0 j}-c_{i j}$ for all pairs of distinct customers, $i$ and $j$. The incremental savings correspond to removing two arcs, $(i, 0)$ and $(0, j)$, from the current solution, and 
instead, including the arc $(i, j)$. In each iteration, the two routes associated with the largest positive cost reduction are merged, assuming the merger is valid with respect to for example, vehicle capacity and that neither arc $(i, 0)$ nor arc $(0, j)$ has been removed yet. In case of symmetric cost or distance matrices, that is, $c_{i j}=c_{j i}$, it is sufficient that both customer $i$ and customer $j$ are directly connected to the depot and belong to distinct routes. A customer, $k$, is directly connected to the depot if at least one of the arcs, $(0, k)$ and $(k, 0)$, is included in the solution. The termination criterion of the Clarke and Wright algorithm states that the algorithm should terminate when there are no valid merges left and/or no more positive cost reductions for merging routes.

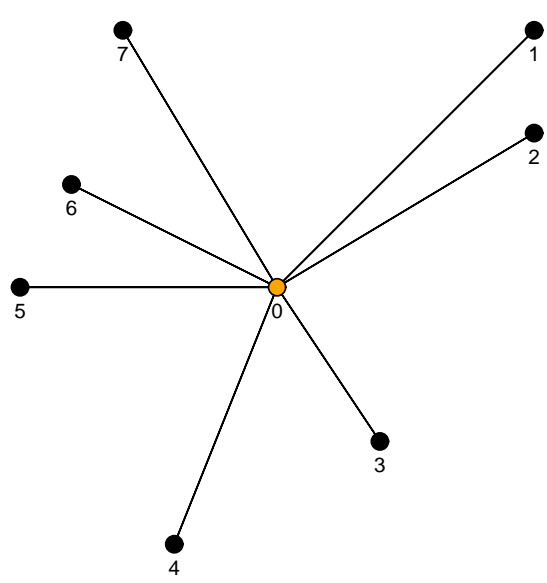

Figure 3.1: A represenation of the initial solution of the Clarke and Wright algorithm for an arbitrary VRP with one depot, seven customers and seven routes. The routes are originating from the depot, goes to the customer and back to the depot.

The network flow problems related to Paper III were solved by Skogforsk $^{4}$ using the FlowOpt software (Forsberg et al., 2005). The software is developed at Skogforsk specifically for the Swedish forest industry. The author of this thesis has not used the FlowOpt software but instead, the optimal costs of the network flow problems, studied in Paper III, are provided by Skogforsk.

\footnotetext{
${ }^{4}$ https://www.skogforsk.se/ (October 2018).
} 


\section{Chapter 4}

\section{Cooperative game theory}

The purpose of this chapter is to provide a general overview of cooperative game theory which is used as an academic tool in this thesis.

A game consists of a set of players, a set of choices the players can make and a number of consequences for each combination of choices. The players do not necessarily have the same choices. An example of a game is the prisoner's dilemma (Tucker, 1950; Tucker, 1983). Two people (the players), A and B, are arrested; both are suspected of having participated in a crime. Each of them can choose either to stay silent or to testify that the other person committed the crime (the choices). The punishments (the consequences) are dependent on their choices; see Table 4.1.

Table 4.1: Outcomes of the prisoner's dilemma.

\begin{tabular}{|c|c|c|}
\hline \multirow{3}{*}{ A stays silent } & B stays silent & B testifies \\
\hline & A: 1 year in prison & A: 3 years in prison \\
\hline & B: 1 year in prison & B: goes free \\
\hline A testifies & $\begin{array}{l}\text { A: goes free } \\
\text { B: } 3 \text { years in prison }\end{array}$ & $\begin{array}{l}\text { A: } 2 \text { years in prison } \\
\text { B: } 2 \text { years in prison }\end{array}$ \\
\hline
\end{tabular}

From a system (the players') point of view, it is best if both people stay silent. However, if B stays silent, then it is better for A to testify, because 0 years in prison is preferable to 1 year. Similarly, if $\mathrm{B}$ testifies, then it is also here better for A to testify because 2 years in prison is preferable to 3 years. Thus, no matter what $\mathrm{B}$ decides to 
do, it is better for A to testify and ultimately, due to symmetry, both people will testify.

In this thesis, cooperative cost games have been used in order to solve the cost allocation problems considered. A cooperative cost game $(N, c)$ consists of a set of numbered players $N=\{1,2, \ldots, n\}$ and a cost function $c$ that is defined $\forall S \subseteq N$, mapped on $\mathbb{R}$. It is common to define $c(\emptyset)=0$ and for simplicity, write $c(i)$ instead of $c(\{i\})$ and write $y(S)$ instead of $\sum_{i \in S} y_{i}$. The cost function $c$ is called the characteristic function, all subsets of $N$ are called coalitions and $N$ itself is called the grand coalition. The values of the characteristic function correspond to costs associated with the coalitions. A solution to a cooperative cost game is a vector $y=\left(y_{1}, y_{2}, \ldots, y_{n}\right) \in \mathbb{R}^{n}$. A solution represents how much each player will pay and can also be called a cost allocation. A cooperative cost game is proper if $c(S)+c(T) \geqslant c(S \cup T), \forall S, T \subseteq N$, $S \cap T=\emptyset$. In this context, proper means that the cost of a coalition is never higher than the collective cost of a partition of the coalition, or in other words, it is always advantageous (or make no difference) to include more players.

If a player wants to increase the possibility of establishing a cooperation, side payments can be used. A player may pay the other players some kind of compensation in order to increase the probability of establishing a cooperation. Let $s_{i j}$ denote the side payment from player $i$ to player $j$. Then the final cost, $y_{k}^{f}$, of player $k$, will be $y_{k}^{f}=y_{k}+\sum_{i \in N}\left(s_{k i}-s_{i k}\right)$. Side payments have been used in, e.g., Paper I and by Agarwal and Ergun (2010). In the case of the prisoner's dilemma, such payments can not be used. The value or utility (years) in the prisoner's dilemma is not transferable, whereas the utility (money) in games such as like those described in this thesis is transferable.

\subsection{Cost allocation methods}

A cost allocation method yields a set, $Y$, of solutions to a cooperative cost game. Some cost allocation methods from the literature are presented below. There are some properties, or fairness criteria, that a cost allocation method may fulfill; see Section 4.1.1. When a cost allocation method is considered in practice, it is arguable that three properties are more relevant than other properties. These three properties are efficiency, individual rationality and group rationality. 
If these three properties are fulfilled, then there is no monetary (short term) incitement to not cooperate.

The descriptions of cost allocation methods are divided into two subsections: variations of the core (see Section 4.1.2); and common cost allocation methods (see Section 4.1.3).

\subsubsection{Solution properties}

In this section, a number of solution properties are listed and defined. The solution properties are referred to in the following sections.

Let $\Phi$ denote a cost allocation method. For a given cooperative cost game $(N, c), \Phi$ yields a set of solutions denoted $Y_{(N, c)}^{\Phi}$.

The cost allocation method $\Phi$ fulfills efficiency if $y(N)=c(N)$, $\forall y \in Y_{(N, c)}^{\Phi}$. That is, the value of the grand coalition should be allocated among the players.

The cost allocation method $\Phi$ fulfills individual rationality if $y_{i} \leqslant c(i), \forall y \in Y_{(N, c)}^{\Phi}, \forall i \in N$. That is, no player should pay more than if acting alone.

The cost allocation method $\Phi$ fulfills group rationality if $y(S) \leqslant c(S), \forall y \in Y_{(N, c)}^{\Phi}, \forall S \subseteq N$. That is, no coalition of players should pay more than the coalition would pay if the coalition acted without the other players. If a cost allocation method fulfills group rationality, then, by definition, it also fulfills individual rationality.

Let $m_{(i, S)}$ denote the marginal cost of a player, $i$, to a coalition, $S$ and be defined as $m_{(i, S)}:=c(S)-c(S \backslash\{i\})$.

The cost allocation method $\Phi$ fulfills uniqueness if $\left|Y_{(N, c)}^{\Phi}\right|=1$. That is, exactly one solution to the cooperative cost game, $(N, c)$, exists according to the cost allocation method, $\Phi$.

\subsubsection{Variations of the core}

The core

The core (Gillies, 1959) is defined as all solutions that fulfill both efficiency and group rationality. Thus, by definition, the core satisfies the three properties efficiency, individual rationality and group rationality. The core is mathematically defined as the set of solutions to 


$$
\begin{aligned}
y(S) & \leqslant c(S), & S \subset N, \\
y(N) & =c(N) . &
\end{aligned}
$$

If a solution satisfies the constraints in (4.1) then the solution is sta$b l e$, or equivalently, the solution is in the core. The constraint set (4.1a) expresses group rationality and the constraint (4.1b) expresses efficiency.

The core rarely contains a single element, but instead, the core is usually either the empty set, or it contains infinitely many solutions, which is problematic from a decision-making point of view. Due to this, the core is rarely used in practice as a stand alone cost allocation method. But since it fulfills efficiency and both rationalities (see Section 4.1.1), it is common to use the core in conjunction with some additional method that reduces the set of solutions.

Having at least one solution is a key aspect to solving cooperative cost games. In order to prevent that the set of solutions is the empty set, Shapley and Shubik (1963) and Shapley and Shubik (1966) present two extensions of the core, namely, the $\varepsilon$-core and the weak $\varepsilon$-core. A third extension, the $v$-core, is used as a part of a larger cost allocation model in Paper I. The differences and similarities between the extensions are explained in the paragraph that follows the defining of the extensions below.

The $\varepsilon$-core

The $\varepsilon$-core is an extension of the core in which the inequality constraints (expressing group rationality) are relaxed by adding $\varepsilon>0$ to the right-hand side for each inequality constraint in (4.1a). The $\varepsilon$-core is defined as the set of solutions to

$$
\begin{aligned}
y(S) & \leqslant c(S)+\varepsilon, \\
y(N) & =c(N) .
\end{aligned}
$$

By using the $\varepsilon$-core, it is possible to guarantee that the set of solutions is nonempty. This is done by choosing a sufficiently large value for $\varepsilon$.

The weak $\varepsilon$-core

For the weak $\varepsilon$-core, the relaxation term is scaled by the size of the corresponding coalition. The weak $\varepsilon$-core is defined as the set of 
solutions to

$$
\begin{aligned}
& y(S) \leqslant c(S)+|S| \cdot \varepsilon, \quad S \subset N, \\
& y(N)=c(N) .
\end{aligned}
$$

Like the $\varepsilon$-core, a nonempty set of solutions can be achieved by choosing a sufficiently large value for $\varepsilon$.

\section{The $v$-core}

An alternative extension of the core is the $v$-core, which is used in Paper I. The right-hand side of the equality constraint (expressing efficiency) in (4.1b) is subtracted by $v \geqslant 0$. The $v$-core is defined as the set of solutions to

$$
\begin{aligned}
y(S) & \leqslant c(S), & S \subset N, \\
y(N) & =c(N)-v . &
\end{aligned}
$$

Similar to the $\varepsilon$-core, a nonempty set of solutions can be achieved by choosing a sufficiently large value for $v$.

The three extensions of the core are similar, in the sense that it is possible to prevent the set of solutions being empty. However, there are some differences. The $\varepsilon$-core relaxes each inequality constraint equally. This means that all coalitions are treated equally. The relaxation can be viewed as the coalitions' acceptance of possibly receiving a higher allocated cost than the cost of the coalition. For a given solution $y$ and coalition $S \subseteq N$, the excess value, $e(S, y):=c(S)-y(S)$, can be viewed as a measure of satisfaction. Some coalitions may have a negative excess value, $e(S, y)$, down to $-\varepsilon$, which means they receive a higher collective allocated cost than if they acted without the others, by a value up to $\varepsilon$. If the weak $\varepsilon$-core is used instead, it is argued that larger coalitions should be willing to accept more negative excess (smaller excess value, $e(S, y)$ ) since there are more players who share the additional cost. This is the reason why the relaxation term is scaled with the size of the corresponding coalition. The $v$-core does not relax any inequality constraint. Instead, the grand coalition cost which is to be allocated among the players, is reduced by a value $v$. Then, the value $v$ must be allocated separately in order for $v$-core to fulfill efficiency. The $v$-core does not have a predefined way of allocating this value. In Paper I, however, the value $v$ is allocated to one specific player and the $v$-core is used as a part of a larger cost allocation model. 


\subsubsection{Common cost allocation methods}

A number of cost allocation methods are used in the papers appended to this thesis. The methods are defined and explained in this section.

\section{The equal profit method}

The aim of the Equal Profit Method (EPM) (Frisk et al., 2010) is to yield a solution in the core such that the largest difference in pairwise relative costs, defined as $\frac{y_{i}}{c(i)}-\frac{y_{j}}{c(j)}$, is as small as possible. If the differences in relative costs are zero, then each player receives an allocated cost equally proportional to their respective individual cost. The EPM is defined as the set of optimal solutions to the problem

$$
\begin{array}{rlrl}
\operatorname{minimize} & f, & \\
\text { subject to } & \frac{y_{i}}{c(i)}-\frac{y_{j}}{c(j)} & \leqslant f, & i \in N, j \in N, \\
y(S) & \leqslant c(S), & S \subset N, \\
y(N) & =c(N) . &
\end{array}
$$

The expression (4.5a) describes the aim to minimize the largest difference in pairwise relative costs which is defined by the constraint set (4.5b), while the constraint sets (4.5c) and (4.5d) define the core.

This is an example of a cost allocation method that uses the core in conjunction with an additional method, in this case minimizing the largest difference in pairwise relative costs. Even though the EPM may exclude a large part of the set of solutions in the core, it does not necessarily yield a unique solution. In Paper II, two examples are given, neither of which has a unique solution according to the EPM.

The EPM is used in Papers I and V.

The equal profit method with lexicography

In Paper II, a version of the EPM is developed, the Equal Profit Method with Lexicography (EPML), and the necessity of the EPML is discussed. Lexicography is used in the EPML and is described below.

Let $\hat{x}=\left[\hat{x}_{1}, \hat{x}_{2}, \ldots, \hat{x}_{k}\right]$ and $\hat{z}=\left[\hat{z}_{1}, \hat{z}_{2}, \ldots, \hat{z}_{k}\right]$ be two lists of the same size. If $\exists q \in \mathbb{N}$ such that $\hat{x}_{i}=\hat{z}_{i}, \forall i<q$ and $\hat{x}_{q}>\hat{z}_{q}$, then $\hat{x}$ is lexicographically greater than $\hat{z}$ and the notation is $\hat{x}>_{L} \hat{z}$. 
Let $s_{y}$ be the nonincreasing list of the values for the differences in relative costs $\frac{y_{i}}{c(i)}-\frac{y_{j}}{c(j)}$ for a given solution, $y$. Then the EPML yields the solution to (4.5) with the lexicographically smallest $s_{y}$.

To put it simply, if the EPM yields a nonunique solution, the allocated costs of some players are ambiguous. When the EPML is used, the differences in relative costs between these players are reduced further. This is an iterative process that can be repeated until a unique solution is found.

The EPML is used in Paper III.

\section{The $\Delta$ equal profit method}

Another issue with the EPM occurs when $c(i) \leqslant 0$ for some player $i$. If $c(i)=0$ then there is a division by zero when relative costs (see constraint set 4.5b) are calculated, and if $c(i)<0$ for some player $i$, then the relative cost will increase when the allocated cost $y_{i}$ decreases. This is illogical and implies that player $i$ pays a larger part of its individual cost by paying less. Additionally, given that $c(i)<0$ and that individual rationality should be fulfilled, then the smallest relative cost for player $i$ is 1 , whereas 1 is the greatest relative cost if $c(i)>0$. The issue of the EPM when $c(i) \leqslant 0$ for some player $i$ is addressed in Paper I. The suggestion is to calculate a lower bound, $l_{i}$, on the allocated cost with respect to the core, (4.1), for each player, $i$, such that $c(i) \leqslant 0$ and, in addition, to define relative costs as $\frac{y_{i}-l_{i}}{c(i)-l_{i}}$ for those players. However, it may be argued that each player should be treated in the same way. Thus, a new cost allocation method, the $\Delta$ Equal Profit Method $(\Delta \mathrm{EPM})$, is presented here, where all relative costs are defined as $\frac{y_{i}-l_{i}}{c(i)-l_{i}}$. The $\Delta$ EPM is defined as the set of optimal solutions to the problem

$$
\begin{array}{rlrl}
\text { minimize } & & & \\
\text { subject to } & \frac{y_{i}-l_{i}}{c(i)-l_{i}}-\frac{y_{j}-l_{j}}{c(j)-l_{j}} & \leqslant f, & i \in N, j \in N, \\
y(S) & \leqslant c(S), & S \subset N, \\
y(N) & =c(N), & &
\end{array}
$$

where $l_{i}$ is the optimal objective function value to the problem

$$
\begin{aligned}
\text { minimize } & y_{i}, \\
\text { subject to } & y(S) \leqslant c(S), \quad S \subset N, \\
& y(N)=c(N) .
\end{aligned}
$$


The value of $l_{i}$ is a lower bound on the cost allocated to player $i$ with respect to the core. The difference $c(i)-l_{i}$ can therefore be seen as a measure of the bargaining potential in the sense that the measure indicates to what extent the player might bargain. It might occur that $l_{i}=c(i)$, which would result in a division by zero (see constraint set $(4.6 \mathrm{~b})$ ) and occurs when $m_{(i, N)}=c(i)$. One way to handle this could be to decide a priori that $y_{i}=c(i)$ for each player $i$ such that $m_{(i, N)}=c(i)$ and exclude them from (4.6b). The $\Delta \mathrm{EPM}$ may be nonunique, thus lexicography can be applied to the $\Delta \mathrm{EPM}$, in a similar fashion as to the EPML.

Currently, the $\triangle \mathrm{EPM}$ is not presented in any paper or journal but is only presented here and in the work of Dahlberg (2015). However, the modified version of the EPM suggested in Paper I is very similar.

\section{The nucleolus}

Let the excess vector $\theta(y)$ be the nondecreasing list containing all excess values, $e(S, y)=c(S)-y(S)$.

The nucleolus (Schmeidler, 1969) is defined as the cost allocation that satisfies both efficiency and individual rationality with the lexicographically largest excess vector, or mathematically, $\{y \in X \mid$ $\left.\theta(y) \geqslant_{L} \theta(\widehat{y}), \forall \widehat{y} \in X\right\}$, where $X=\left\{y \in \mathbb{R}^{n} \mid y(N)=c(N), y_{i} \leqslant c(i)\right\}$.

Procedures to calculate the nucleolus can be found in e.g., Paper III or in the works of Dragan (1981) and Kopelowitz (1967) and involves solving a number of optimization problems iteratively.

From a decision-making point of view, two positive properties of the nucleolus are that if the core is nonempty then the solution according to the nucleolus is in the core, as shown by Schmeidler (1969). ${ }^{1}$ The other property is that the solution is unique. A drawback is that the nucleolus may be empty. This occurs for instance when $\sum_{i \in N} c(i)<c(N)$.

The nucleolus is used in Papers I and III-V.

\footnotetext{
${ }^{1}$ This is easily understood since any solution in the core (of a given cooperative cost game) has a nonnegative excess vector, whereas the excess vector of any efficient solution (fulfills efficiency) not in the core has at least one negative excess value. Thus, the excess vector of any solution in the core is lexicographically greater than the excess vector of any efficient solution not in the core.
} 


\section{The Shapley value}

The Shapley value (Shapley, 1953) is a combinatorial construction where the marginal cost, $m_{(i, S)}=c(S)-c(S \backslash\{i\})$, plays a major role. The grand coalition can be formed when the players are added sequentially. There are $|N|$ ! ways to form the grand coalition, starting with the empty set. For a specific player, $i$, and a specific coalition, $S$, such that $i \in S$, there are $(|S|-1)$ ! ways to form the coalition $S \backslash\{i\}$ and $(|N|-|S|)$ ! ways to form the grand coalition, starting from $S$. The Shapley value for a specific player, $i$, is a weighted average of the marginal costs, where the weights correspond to the number of ways the grand coalition can be formed, given that the first players to join are those in $S \backslash\{i\}$. A more compact equation is

$$
y_{i}=\sum_{S \subseteq N, S \neq \emptyset} \frac{(|S|-1) !(|N|-|S|) !}{|N| !} \cdot(c(S)-c(S \backslash\{i\})) .
$$

It should be noted that the Shapley value yields a unique solution. The Shapley value is easy to compute with given characteristic function values but there is no guarantee that the Shapley value yields a solution in the core.

The Shapley value is used in Papers I and III-V.

\subsection{Examples of applications}

Cooperative game theory has been used in the application of transportation planning. A few examples from the literature can be found in Section 1.2, Chapter 2 as well as in the papers appended to this thesis. For a more in-depth coverage, Guajardo and Rönnqvist (2016) provide an extensive survey of cost allocation methods in this context. They identify both different types of problems and different types of cost allocation methods that are used. However, cooperative game theory has also been used in many other applications. This section consists of a general overview of both classic applications as well as some more recent ones in order to show the broad spectrum of applications in which cooperative game theory has been used.

Multiple stakeholders may invest in and/or construct some shared infrastructure, facilities or resources, for instance, a water reservoir (Young, 1985), a water supply system (Young et al., 1982) or a facility for transportation (Puerto et al., 2001). In Young (1985), the construction cost of the water reservoir depends on which purposes (e.g., 
power supply, irrigation and water consumption for households) it will fulfill. In Young et al. (1982), the water supply system might need to be expanded in order to connect stakeholders (in this case municipalities) and thus, the construction cost depends on the number of new pipelines needed. In Puerto et al. (2001), the construction cost of the facility depends on the location at which it is constructed. Puerto et al. (2001) include both a fixed construction cost and a transportation cost proportional to the Euclidean distance between the facility and the users of the facility. In Papers I, IV and V, a facility is shared; however, no investment or construction cost is considered, because the shared facility is assumed to already exist. In practice, however, it is plausible that no such facility exists. In that case, the investment or construction cost might need to be included in the cost allocation problem.

Some shared infrastructure, facilities or resources may need maintenance, for instance, runways at airports (Littlechild and Owen, 1973; Littlechild and Thompson, 1977) and railway systems (Fragnelli et al., 2000; Norde et al., 2002). In these papers, the maintenance costs are allocated among the stakeholders and it is natural to assume that frequent users who cause most wear and tear on the infrastructure should be allocated most of the maintenance cost. In the papers appended to this thesis, only operational costs are considered. However, from a long term perspective, maintenance is an important activity in many applications and generates additional costs that need to be covered by the cooperating stakeholders.

Another example of resource sharing is the bus game (Fragnelli et al., 2004) in which travel agencies arrange trips. Even though they might only need a strict subset of the seats of a bus, they still need to rent the whole bus. The characteristic function values are the number of buses required for the total number of passengers related to each coalition. This is similar to many maritime applications in which many stakeholders share ships, for instance carrier alliances in liner shipping (Agarwal and Ergun, 2010). Some of the cooperating stakeholders in liner shipping are nonvessel operators, that is, they do not own any ships. In Papers I, IV and V, like the nonvessel operators, the municipality does not own any vehicles. However, the case of the municipality is one step further; the municipality does not even have any operations of its own. The aim of the bus game is to use as few buses as possible and achieve high loading factors. This is commonly an underlying aim for logistics companies, projects and systems as 
well as in the transportation planning applications considered in this thesis.

In the context of supply chain management, Dror and Hartman (2011) present a survey of inventory games, in which a company must meet the demand of their customers by ordering the goods from suppliers. The company has an inventory and the problem is to decide what quantity to order from the suppliers. By cooperating with other companies at the same level in the supply chain, the ordering cost (e.g., administrative work) may be reduced and a quantity discount might apply. The ordering cost of the grand coalition is allocated among the cooperating companies. The forest companies in Paper III are cooperating stakeholders at the same level in the supply chain, namely the transportation of wood from harvest areas to industries.

In this thesis, there are several examples of cooperation in the context of transportation planning discussed and some more classic examples are presented here. In the travel expenses game or the travelling salesman problem cost game (Young, 1985; Dror, 1990), a lecturer is invited to speak in a number of cities. Each city is a player in the cooperative cost game and the characteristic function value is the lecturer's travel expenses for being able to give the presentation in each city of the coalition. That is, the characteristic function value, $c(S)$, is defined as the optimal cost to the travelling salesman problem ${ }^{2}$ associated with $S$. The home city of the lecturer needs to be included in the travelling salesman problem even though the home city is not included in the cooperative cost game. In the papers appended to this thesis, there is one stakeholder, namely the initiator of the cooperation, who must be included or else there is no cooperation. The role of the initiator is somewhat similar to the cooperation as the role of the home city is to the travelling salesman problem.

An extension of the travel expenses game is the vehicle routing game (Göthe-Lundgren et al., 1996; Engevall et al., 2004), in which the cost of a Vehicle Routing Problem (VRP) is allocated among the customers in the VRP. Göthe-Lundgren et al. (1996) consider the nucleolus to allocate the cost and apply it to a number of numerical examples. Engevall et al. (2004) study a case of gasoline transportation to gas stations. The gas stations are the customers in the VRP as well as the stakeholders in the formulated cooperative cost game. This is different to the cooperative cost games presented in Papers I,

\footnotetext{
${ }^{2}$ A classic mathematical problem, which can be seen as a special case of the vehicle routing problem; see Section 3.2.
} 
IV and V, in which the stakeholders are a number of freight forwarders with a number of customers each. The size of the grand coalition, $N$, is much larger in the vehicle routing game than in the cooperative cost games presented in Papers I, IV and V. 


\section{Chapter 5}

\section{Summary of the papers}

In this chapter, Papers $I-V$ are summarized and the contribution of the author of this thesis, as well as the contribution to the papers of the coauthors are described. In addition, it is stated where each paper is published and the conferences at which some of the results have been presented (if applicable).

\subsection{Summary of Paper I}

The focus of Paper I is on the consolidation of goods as a means to improve urban goods distribution, and the paper addresses the need for business models that describe the stakeholders' roles and interrelationships in terms of how to handle and allocate costs. A cost allocation model based on concepts from cooperative game theory is developed and the model is tested on a numerical example as a proof of concept. The numerical example involves a cooperation among the municipality and three freight forwarders using a common City Distribution Center (CDC), and each freight forwarder has a number of goods receivers or customers who require delivery of goods. The cost allocation problem is solved by formulating a cooperative cost game in characteristic function form, and costs are estimated by solving transportation planning problems modeled as Vehicle Routing Problems (VRPs) in which the total operational cost is minimized.

A key-feature of Paper I, complementing previous research, is the inclusion of the municipality and its role in the cooperation. The municipality is a dominant player, an enabler of the cooperation and 
is included in the cost allocation problem. The municipality itself has no operational cost, which is not normally the case for a stakeholder responsible for transportation planning. That is, the municipality's individual cost, $c(i)$, is equal to 0 and it is not possible to use the Equal Profit Method (EPM) since the relative cost, $\frac{y_{i}}{c(i)}$, of the municipality is not defined (division by zero). The relative cost of the municipality is instead defined in the same way as to that of the $\Delta$ Equal Profit Method $(\Delta \mathrm{EPM})$, that is, $\frac{y_{i}-l_{i}}{c(i)-l_{i}}$.

It is suggested that the municipality uses side payments in order to maintain the cooperation. This is done by using the $v$-core and letting the municipality pay the additional cost $v$. Cost allocations according to the modified version of the EPM (with the redefined relative cost for the municipality), the Shapley value and the nucleolus, are compared and analyzed. A number of scenarios, or numerical instances, are studied; however, the cost allocation according to the Shapley value is not stable in any of the studied scenarios. In one scenario when the municipality uses side payments and the nucleolus is considered, the municipality receives a positive net profit (including the side payments).

The contribution of Paper I is a conceptual framework in which freight forwarders and the municipality can cooperate with regards to urban goods distribution and share the total operational costs. Additional contributions are the analyze of how the total operational cost might be allocated fairly among the stakeholders, as well as suggestions as to how additional side costs generated as a result of cooperating can be handled.

A natural continuation of Paper I is to include a more realistic scenario and perhaps also real-life data. This is undertaken in Papers IV and V. Possible versions of the transportation planning problem are to include time window constraints, to use a heterogeneous fleet, and to account for dynamic travel times, to name a few. Other objectives which stem from the stakeholders' different objectives could also be incorporated. These objectives might include nonmonetary costs such as emissions and customer satisfaction.

The full citation for Paper I is:

Dahlberg, J., Engevall, S., and Göthe-Lundgren, M. (2018). "Consolidation in Urban Freight Transportation - Cost Allocation Models". Asia-Pacific Journal of Operational Research 35, p. 1850023.

The coauthors have contributed with the research idea for Paper I and with an early draft of the manuscript. The authors have jointly 
contributed in terms of writing and analyzing results. The author of this thesis has had full responsibility for the the implementation of solution methods, and data handling.

Parts of the results found in Paper I have been presented by the author of this thesis at the following conferences:

- Nationella konferensen i transportforskning (The Swedish Transportation Research Conference), Gothenburg, Sweden, October 2013.

- Svenska operationsanalyskonferensen (The Swedish Conference in Operations Research), Gothenburg, Sweden, October 2013.

\subsection{Summary of Paper II}

The purpose of Paper II is to address an issue (nonuniqueness) with the EPM. The issue is addressed by introducing a development of the EPM, namely the Equal Profit Method with Lexicography (EPML). In some cases, the cost allocation according to the EPM is any of infinitely many cost allocations, which is problematic from a decisionmaking point of view. This means that a player's allocated cost might depend on arbitrary factors such as the numbering of the players. The EPML reduces the number of cost allocations to one, a unique solution to the cost allocation problem (assuming at least one feasible solution exists). This is done by identifying which players' allocated cost is not unique (according to the EPM) and then minimizing the difference in relative costs between those players further. The EPML is similar to the nucleolus in the sense that both the nucleolus and the EPML are defined using lexicography, and the procedures to calculate them are similar. Specifically for the EPML, each time the difference in relative costs is minimized, at least two new players' allocated costs become unique. A unique solution is therefore found in a finite number of steps (identification + reoptimization) less than or equal to half of the number of players (with the exception of one-player games). The fundamental idea of the EPM is respected and preserved by the EPML. Some numerical examples are presented to illustrate the differences between the EPM and the EPML. The EPML is later used in Paper III.

The contribution of Paper II is the introduction of a development of the EPM for allocating costs. The proposed version is the EPML, 
which, in contrast to the former method, guarantees to yield at most one solution to any cost allocation problem.

The full citation for Paper II is:

Dahlberg, J., Göthe-Lundgren, M., and Engevall, S. (2017). "A note on the nonuniqueness of the Equal Profit Method". Applied Mathematics and Computation 308, pp. 84-89.

The author of this thesis has been the main contributor to $\mathrm{Pa}-$ per II and the contribution includes formulating the research idea, writing the manuscript, and designing the analysis. The coauthors have contributed to Paper II by actively taking part in discussions as well as by providing feedback on the manuscript.

\subsection{Summary of Paper III}

The aim of Paper III is to provide conditions that are as good as possible to achieve a large cooperation. The cooperation is preceded by a simultaneous invitation sent to a number of stakeholders, in this case forest companies, and each stakeholder either accepts or declines a preliminary cost allocation when announcing its transportation needs (e.g., supplies, demands and locations). The announcements occur sequentially, and a sequence of stakeholders can be viewed as a path in a network of possible collaborations, see Figure 5.1, starting with the empty set or, in practice, with any single stakeholder, and the size of the cooperation increases until the end, where (ideally) all stakeholders cooperate.

Who will agree to cooperate is not predefined but in the paper it is assumed that larger cooperations are preferable to smaller cooperations. Each time a new stakeholder considers joining the cooperation, a new cost allocation is calculated. Whether or not a stakeholder will, or will be allowed to, join the cooperation is based on the new cost allocation.

A Monotonic Path (MP) is a path in the network of possible collaborations, such that all stakeholders benefit (or are unaffected) when a new stakeholder joins. In other words, no stakeholder has an economic incentive to leave the cooperation. The path may lead to a full cooperation in which all the invited stakeholders join, at which point it becomes a complete MP. The number of complete MPs is calculated by enumerating all possible paths in the network. Similar work has been done by Cruijssen et al. (2005) where groups 


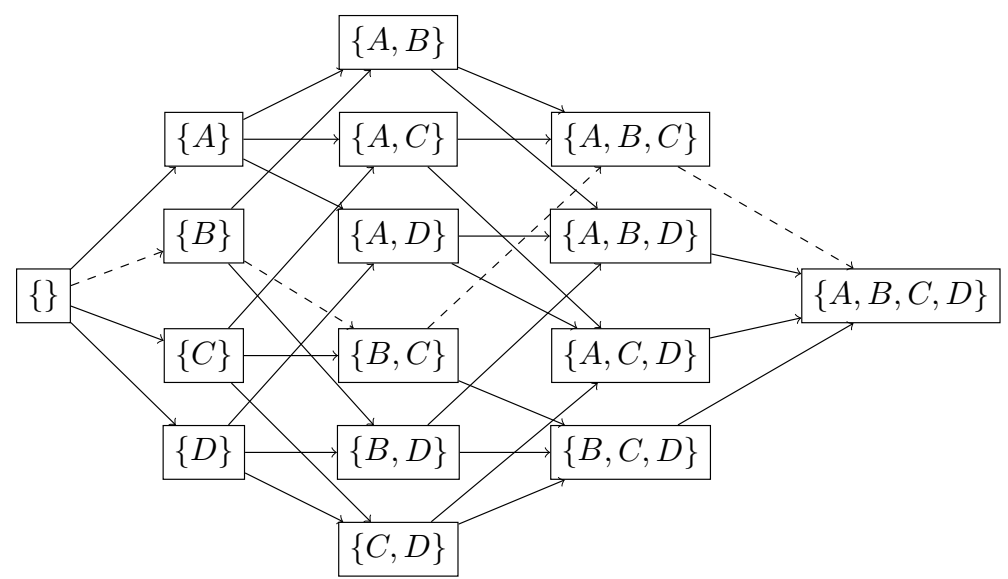

Figure 5.1: Conceptual example of a network of possible collaborations of four companies, $\{A, B, C, D\}$, of which one path, $B, C, A, D$, is a collection of dashed lines. Source: Paper III.

of shippers with high synergies are proactively selected by a Logistics Service Provider (LSP); that is, the LSP chooses a specific path in the network of possible collaborations. However, unlike Cruijssen et al. (2005), all possible paths are considered in Paper III and thus no stakeholder is proactively selected.

A number of cost allocation mechanisms, based on common cost allocation methods from cooperative game theory, are developed and tested in Paper III. The purpose of enumerating all possible paths is to obtain an indication of how successful each cost allocation mechanism is in regards to the aim of the paper. It is shown that a stable cooperation can be achieved, but that the likelihood of achieving a stable cooperation is dependent on the cost allocation mechanism used. Two of the ten suggested cost allocation mechanisms guarantee a stable cooperation, regardless of the order in which the stakeholders join, and the two cost allocation mechanisms ensure that all paths are complete MPs, under the assumption that the cooperative cost game is proper. A proof that this holds for a general case is given in the paper. In this context, proper means that, from a system optimal perspective, it is never disadvantageous to form a larger cooperation. Proper games are defined mathematically at the beginning of Chapter 4 and in Paper III.

The contribution of Paper III is a framework to establish a cooperation among stakeholders when the stakeholders join the cooperation 
sequentially and the order in which they join is stochastic. The cooperation is motivated by using the cost allocation mechanisms that are developed in the paper to make fair cost allocations. The cost allocation mechanisms are additional contributions.

The results in Paper III are based on a specific case (Frisk et al., 2010), and thus, the extent to which the results are case sensitive is uncertain. However, no case-specific assumptions are made. It is therefore plausible that the results can be generalized. A natural continuation of Paper III is to apply the ideas to other cases and transportation planning applications.

The full citation for Paper III is:

Dahlberg, J., Engevall, S., Göthe-Lundgren, M., Jörnsten, K., and Rönnqvist, M. (2018). "Incitements for transportation collaboration by cost allocation". Central European Journal of Operations Research, pp. 1-24.

The coauthors have contributed with the research idea of Paper III and with an early draft of the manuscript. The data are given a priori and are presented in research papers written prior to Paper III. The author of this thesis has contributed to Paper III by writing a significant part of the manuscript and has had full responsibility for the implementation of the solution methods. The coauthors have additionally had an active role in the processes of writing, providing continuous feedback and analyzing results.

Parts of the results in Paper III have been presented by the author of this thesis at the following conferences:

- Nationella konferensen i transportforskning (The Swedish Transportation Research Conference), Norrköping, Sweden, October 2014.

- The $4^{\text {th }}$ Symposium of the European Association for Research in Transportation, Copenhagen, Denmark, September 2015.

\subsection{Summary of Paper IV}

In Paper IV, a cooperation among stakeholders responsible for the distribution of goods in an urban area is considered. The problem structure is similar to that of Paper I, in the sense that there are three freight forwarders and a municipality using a common City Distribution Center (CDC) and the transportation planning problem is modeled as a VRP. 
The purpose of Paper IV is to address some of the difficulties of using common methods for allocating costs in real-life-sized problems in the context cooperative transportation planning of urban goods distribution. The main difficulty is to compute optimal solutions to large VRPs. In Paper IV, this difficulty is tackled by developing a method for allocating costs based on approximated VRP costs. The VRP costs are approximated by using a commercial solver (Gurobi Optimization, 2016), providing a feasible initial solution and setting a termination criterion of accepting a nonzero Mixed Integer Programming (MIP) gap. The MIP gap can be seen as an estimate of how good the best found feasible solution is. The best found feasible solution is optimal if the MIP gap is 0. By accepting a nonzero MIP gap, we retriev an upper and a lower bound of the optimal VRP cost for each VRP from the solver. The upper bound corresponds to the best found feasible solution and the lower bound is calculated and provided by the solver. The cost allocation problem is modeled as a cooperative cost game and the characteristic function is formulated as a convex combination of the upper and the lower bounds of the optimal VRP cost.

The viability of the method is verified by computational times that are reasonable relative to the planning horizon. The quality of the method is verified by comparing the cost allocations given by the method with cost allocations based on optimal costs. The differences between the cost allocations are small. The practicability of the method is verified by testing the method on four instances of different sizes that are based on selected real-life data from a dataset. The real-life data were gathered in the spring of 2004, when a demonstration project, SAMLIC (Eriksson et al., 2006; Eriksson and Svensson, 2008) took place in Linköping, a medium-sized city in Sweden.

The contribution of Paper IV is a viable and practical method that could be used in real-life situations to allocate costs among cooperating stakeholders responsible for the distribution of goods in an urban area. In this context, viable and practical means that the method has acceptable computational times and produces reasonable numerical results, even for real-life-sized problems corresponding to a medium-sized city in Sweden.

In order to be able to generalize the results, a natural continuation is to test the method on other cases and transportation planning applications. The method can be generalized. However, the viability, quality and practicability needs to be tested further. 
The full citation for Paper IV is:

Dahlberg, J., Engevall, S., Göthe-Lundgren, M., and Karlsson, J. (2018). "Consolidation in urban goods distribution - Cost allocation based on approximate solutions".

Paper IV has not yet been accepted for publication.

The research idea for Paper IV has been developed during discussions among the authors. The author of this thesis has contributed to Paper IV by writing the vast majority of the text and has had full responsibility for the implementation of solution methods, and data handling. All the authors have contributed to Paper IV during the discussions and analysis of the results, and the coauthors have also contributed by providing feedback on the manuscript.

Parts of the results in Paper IV have been presented by the author of this thesis at the following conferences:

- The $9^{\text {th }}$ Triennial Symposium on Transportation Analysis (TRISTAN IX), Oranjestad, Aruba, June 2016.

- Nationella konferensen i transportforskning (The Swedish Transportation Research Conference), Lund, Sweden, October 2016.

- Nationella konferensen i transportforskning (The Swedish Transportation Research Conference), Stockholm, Sweden, October 2017.

- 2017 INFORMS Annual Meeting, Houston TX, USA, October 2017.

\subsection{Summary of Paper $\mathrm{V}$}

In Paper V, methods introduced in Papers I and IV are developed further. The problem structure is similar to that of Papers I and IV. The municipality and three freight forwarders can cooperate and use a common CDC. The transportation planning problem is modeled as a type of VRP, and the characteristic function associated with the cost allocation problem is defined to be the upper bound of the optimal cost. The upper bound corresponds to the objective function value of the best found feasible solution, which may or may not be the optimal solution.

The case considered in Paper V is based on real-life data from three freight forwarders operating in Norrköping, a medium-sized city 
in Sweden, during the spring of 2016 and 2017. Three instances are constructed, and are based on all transports to the city center of Norrköping on distinct days (one for each instance).

Three new aspects are studied in Paper V. 1) The municipality can use road tolls to incentivize cooperation. This is done by applying road tolls for vehicles that are not using the CDC, that is, vehicles owned by freight forwarders who are not cooperating. 2) In the case of a cooperation, two types of vehicle fleets may be used for the distribution of goods; either a fleet of diesel vehicles, or a fleet of electric vehicles. 3) Both economic (total operational cost) and environmental impacts $\left(\mathrm{CO}_{2}\right.$ emissions) are estimated.

The contribution of Paper $\mathrm{V}$ is the further development of the models and methods developed in Papers I and IV which includes road tolls and alternative vehicle fleets.

Conclusions:

1) One of the freight forwarders does not cooperating in the most economically efficient and environmentally friendly solution;

2) The solution in which all the freight forwarders cooperate is the solution with the shortest travel distance in the city center, which should, in general, have the least impact on congestions;

3) Using road tolls is a possible method to incentivize cooperation.

However, the results must be further investigated in order to verify the conclusions that are drawn.

The full citation for Paper V is:

Dahlberg, J., Engevall, S., Göthe-Lundgren, M., and Karlsson, J. (2018). "Improving urban goods distribution using road tolls, collaboration and cost allocation".

Paper $\mathrm{V}$ is a working paper and has not yet been submitted to a conference or a journal.

The research idea for Paper V has been developed during discussions among the authors. Some of the data are directly provided by three freight forwarders in conjunction with a Master's thesis, supervised by the author of this thesis and conducted in the spring of 2017. The author of this thesis has contributed to Paper V by writing the vast majority of the manuscript and has had full responsibility for the implementation of solution methods, and data handling. 



\section{Chapter 6}

\section{Conclusions and future research}

The purpose of this chapter is to summarize and to conclude this thesis, and to relate it to the literature of the past and present as well as to suggest possible future research.

\subsection{Short summary}

Five papers are appended to this thesis and two types of transportation planning applications are considered, namely

1) the distribution of goods bound for urban areas (Papers I, IV and $\mathrm{V}$ ) and

2) the transportation of wood between harvest areas and industries (Paper III).

In this thesis, cooperative game theory is used as an academic tool to study the cooperation among stakeholders in the cooperative transportation planning applications and to solve the cost allocation problems associated with the cooperation.

In Papers I, IV and V, the municipality undertakes a specific role as the enabler and initiator of the cooperation among the freight forwarders that are responsible for the goods distribution in an urban area. Paper I is a proof of concept, demonstrating the feasibility of using the method developed in the paper in the context of urban 
goods distribution. The method is developed further in Paper IV to make it suitable for real-life-sized problems, and in Paper V, the use of tolls and different vehicle fleets are incorporated into the method.

In Paper III, a different perspective of cooperation is studied, namely the process of establishing a cooperation where the stakeholders, in this case forest companies, join the cooperation sequentially and the order in which the stakeholders join is stochastic. Each time a new stakeholder joins the cooperation, a new cost allocation is calculated. Whether or not a stakeholder will, or will be allowed to, join the cooperation is based on the new cost allocation. It is shown that despite the stochasticity, a stable cooperation among all stakeholders can be achieved by using methods developed in the paper.

Paper II is mainly a methodological paper without any specific application context and contributes to the literature of cooperative game theory through the introduction of a development of the Equal Profit Method (EPM) for allocating costs. The proposed version is the Equal Profit Method with Lexicography (EPML), which, in contrast to the former method, guarantees to yield at most one solution to any cost allocation problem.

\subsection{Conclusions}

As mentioned in Chapter 1, the aim of this thesis is to contribute to the research of cooperative transportation planning by using concepts from cooperative game theory and to develop methods for allocating costs among cooperating stakeholders.

Such methods are developed in Papers I-V. Some of the gaps in the literature that are filled are the following: 1) In the literature, stakeholders are commonly treated equally. However, in reality, it can be argued that in some cases, the stakeholders do not have equal power; this imbalance should be taken into account. This imbalance is exemplified in Papers I and III-V, where a dominant player is included. The dominant player is the initiator and enabler of the cooperation. 2) Furthermore, in the literature, the costs that are associated with the cost allocation problem are commonly assumed to be optimal costs. This is not the case in Papers IV and V in which the costs are approximated. The reason for not finding optimal costs is that large and complicated transportation planning problems, for instance Vehicle Routing Problems (VRPs), based on real-life data 
are not practical and it is sometimes not even possible to solve them to optimality.

As mentioned in Chapter 1, the purpose of this thesis is to provide models and methods which can be used to support the decisionmaking process of transportation planning to establish cost-efficient and stable cooperations. This has been done by demonstrating the potential of cooperation and by suggesting how costs can be allocated fairly in different transportation planning applications.

In this thesis, cost-efficient cooperations are achieved in cooperative transportation planning using concepts from cooperative game theory and methods developed in this thesis. Thus, using models and methods developed in this thesis may lead to economic sustainability. However, social sustainability is not quantified or discussed and environmental sustainability is only partly touched on in Paper V in terms of assessing environmental impact by using simplified emission models (estimating $\mathrm{CO}_{2}$ emissions). Nonetheless, it is argued that cooperative transportation planning has (a potential to have) a positive impact on both the global and the local environment, as well as on social aspects in livable cities. This positive impact can be achieved by using certain types of vehicles or by reducing the number of vehicles used, the number of visits made, and the distances travelled.

\subsection{Future research}

In order to verify that a cooperation in cooperative transportation planning is (in all dimensions) fully sustainable requires further investigation as well as methods and approaches from other research fields, to complement the methods used in this thesis.

A natural continuation of Papers III and IV is to apply the ideas and test the methods on other cases and transportation planning applications. The method presented in Paper IV can be generalized. However, the viability, quality and practicability would need to be tested further.

In Paper V, the municipality uses road tolls and coordinates the use of a common City Distribution Center (CDC) to incentivize the cooperation among a number of freight forwarders. However, the freight forwarders might be incentivized to use a common CDC without the assistance of the municipality. The municipality can use regulations, road tolls and other types of fees to incentivize this type of 
cooperation. The level of road tolls and fees are decided by the municipality and the outcome is the actions taken by the freight forwarders. Such interaction between the municipality and the freight forwarders may lead to an interesting type of noncooperative game between the municipality and the freight forwarders. Noncooperative games are beyond the scope of this thesis, but this particular noncooperative game is definitely an interesting path to pursue.

Lastly, the $\Delta$ Equal Profit Method ( $\triangle \mathrm{EPM})$ has some interesting characteristics. It is based on the magnitude of some bargaining potential, rather than absolute costs. A player with higher bargaining potential should have larger cost savings. A further investigation into the characteristics, properties and usefulness of the $\triangle \mathrm{EPM}$ is a worthy avenue for future research. 


\section{Bibliography}

Agarwal, R. and Ergun, O. (2010). "Network design and allocation mechanisms for carrier alliances in liner shipping". Operations Research 58, pp. 1726-1742.

Ahuja, R. K., Magnanti, T. L., and Orlin, J. B. (1993). Network Flows. Prentice Hall, Upper Saddle River, NJ.

Allen, J., Piecyk, M., Piotrowska, M., McLeod, F., Cherrett, T., Ghali, K., Nguyen, T., Bektas, T., Bates, O., Friday, A., Wise, S., and Austwick, M. (2018). "Understanding the impact of ecommerce on last-mile light goods vehicle activity in urban areas: The case of London". Transportation Research Part D: Transport and Environment 61, pp. 325-338.

Allen, J., Thorne, G., and Browne, M. (2007). BESTUFS Good practice guide on urban freight transport. Tech. rep. BESTUFS. www. bestufs.net.

Ambrosino, G., Boero, M, Di Bugno, M, Guerra, S, and Librato, A (2007). "A centre for eco friendly city freight distribution: Urban logistics innovation in a mid-size historical city in Italy". ICL $200 \%$.

Andalaft, N., Andalaft, P., Guignard, M., Magendzo, A., Wainer, A., and Weintraub, A. (2003). "A problem of forest harvesting and road building solved through model strengthening and lagrangean relaxation". Operations Research 51, pp. 613-628.

Bailey, E., Unnikrishnan, A., and Lin, D.-Y. (2011). "Models for minimizing backhaul costs through freight collaboration". Transportation Research Record: Journal of the Transportation Research Board, pp. 51-60. 
Bengtsson, M. and Kock, S. (2000). "Coopetition in business networks - To cooperate and compete simultaneously". Industrial Marketing Management 29, pp. 411-426.

Bertsimas, D. and Tsitsiklis, J. N. (1997). Introduction to Linear Optimization. Vol. 6. Athena Scientific, Belmont, MA.

Björklund, M. and Gustafsson, S. (2015). "Toward sustainability with the coordinated freight distribution of municipal goods". Journal of Cleaner Production 98, pp. 194-204.

Boden, T. A., Marland, G., and Andres, R. J. (2017). Global, regional, and national fossil fuel CO2 emissions. Tech. rep. Carbon Dioxide Information Analysis Center, Oak Ridge National Laboratory, U.S. Department of Energy, Oak Ridge, TN.

Browne, M., Woodburn, A., and Allen, J. (2007). "Evaluating the potential for urban consolidation centres". European Transport 35, pp. $46-63$.

Browne, M., Allen, J., and Leonardi, J. (2011). "Evaluating the use of an urban consolidation centre and electric vehicles in central London". IATSS Research 35, pp. 1-6.

Cherrett, T., McLeod, F., Maynard, S., Hickford, A., Allen, J., and Browne, M. (2009). "Understanding retail supply chains to enable greener logistics". The Westminster Research online digital archive, University of Westminster, westminsterresearch.wmin.ac.uk/id/eprint/9086.

Clarke, G. and Wright, J. W. (1964). "Scheduling of vehicles from a central depot to a number of delivery points". Operations Research 12 , pp. $568-581$.

Crainic, T. G., Ricciardi, N., and Storchi, G. (2009). "Models for evaluating and planning city logistics systems". Transportation Science 43, pp. 432-454.

Cristea, A., Hummels, D., Puzzello, L., and Avetisyan, M. (2013). "Trade and the greenhouse gas emissions from international freight transport". Journal of Environmental Economics and Management 65, pp. 153-173. 
Crowder, H. and Padberg, M. W. (1980). "Solving large-scale symmetric travelling salesman problems to optimality". Management Science 26, pp. 495-509.

Cruijssen, F., Borm, P., Fleuren, H., and Hamers, H. (2005). "Insinking: A methodology to exploit synergy in transportation". CentER Discussion Paper 2005-121. Tilburg University, core.ac.uk/download/pdf/6651222.pdf.

Dahlberg, J. (2015). Cooperative Transportation Planning and Cost Allocation. Licentiate Thesis no 1726, Linköping university, Linköping.

D'Amours, S., Rönnqvist, M., and Weintraub, A. (2008). "Using operational research for supply chain planning in the forest products industry". INFOR: Information Systems and Operational Research 46, pp. 265-281.

Dantzig, G. and Ramser, J. (1959). "The truck dispatching problem". Management Science 6, pp. 80-91.

Della Croce, F., Koulamas, C., and T'kindt, V. (2017). "A constraint generation approach for two-machine shop problems with jobs selection". European Journal of Operational Research 259, pp. 898905 .

Diziain, D., Ripert, C., and Dablanc, L. (2012). "How can we bring logistics back into cities? The case of Paris metropolitan area". Procedia - Social and Behavioral Sciences 39. Ed. by E. Taniguchi and R. G. Thompson, pp. 267-281.

Dragan, I. (1981). "A procedure for finding the nucleolus of a cooperative n-person game". Zeitschrift für Operations Research 25, pp. $119-131$.

Dror, M. (1990). "Cost allocation: The traveling salesman, binpacking, and the knapsack". Applied Mathematics and Computation 35, pp. 191-207.

Dror, M. and Hartman, B. (2011). "Survey of cooperative inventory games and extensions". The Journal of the Operational Research Society 62, pp. 565-580. 
Duin, J. van, Tavasszy, L., and Quak, H. (2013). "Towards E(lectric)urban freight: First promising steps in the electric vehicle revolution". Trasporti Europei 54, pp. 1-9.

Engevall, S., Göthe-Lundgren, M., and Värbrand, P. (2004). "The heterogeneous vehicle-routing game". Transportation Science 38, pp. $71-85$.

Eriksson, J. and Svensson, T. (2008). Efficiency in goods distribution collaboration in cities - SAMLIC. Tech. rep. The Swedish National Road and Transport Research Institute (VTI), Linköping.

Eriksson, J., Karlsson, R., Fors, T., Fredholm, O., Lång, A.-M., and Svensson, T. (2006). SAMLIC - Pilotförsöket. Tech. rep. The Swedish National Road and Transport Research Institute (VTI), Linköping.

Forsberg, M, Frisk, M, and Rönnqvist, M (2005). "FlowOpt - A decision support tool for strategic and tactical transportation planning in forestry". International Journal of Forest Engineering 16, pp. 101-114.

Fragnelli, V., García-Jurado, I., Norde, H., Patrone, F., and Tijs, S. (2000). "How to Share Railways Infrastructure Costs?" In: Game Practice: Contributions from Applied Game Theory. Ed. by F. Patrone, I. García-Jurado, and S. Tijs. Springer, Boston, MA, pp. 91-101.

Fragnelli, V., Garcia-Jurado, I., and Méndez-Naya, L. (2004). "A note on bus games". Economics Letters 82, pp. 99-106.

Franceschetti, A., Demir, E., Honhon, D., Woensel, T. V., Laporte, G., and Stobbe, M. (2017). "A metaheuristic for the timedependent pollution-routing problem". European Journal of Operational Research 259, pp. 972 -991.

Frisk, M., Göthe-Lundgren, M., Jörnsten, K., and Rönnqvist, M. (2010). "Cost allocation in collaborative forest transportation". European Journal of Operational Research 205, pp. 448-458.

Gillies, D. B. (1959). "Solutions to general non-zero-sum games". In: Contributions to the Theory of Games IV. Ed. by A. W. Tucker and R. D. Luce. Annals of Mathematics Studies. Princeton University Press, Princeton, NJ, pp. 47-85. 
Gilmore, P. C. and Gomory, R. E. (1961). "A linear programming approach to the cutting-stock problem". Operations Research 9, pp. 849-859.

Göthe-Lundgren, M., Jörnsten, K., and Värbrand, P. (1996). "On the nucleolus of the basic vehicle routing game". Mathematical Programming 72, pp. 83-100.

Guajardo, M. and Rönnqvist, M. (2015). "Operations research models for coalition structure in collaborative logistics". European Journal of Operational Research 240, pp. 147-159.

Guajardo, M. and Rönnqvist, M. (2016). "A review on cost allocation methods in collaborative transportation". International Transactions in Operational Research 23, pp. 371-392.

Gurobi Optimization, I. (2016). Gurobi Optimizer Reference Manual. www.gurobi.com.

Çimen, M. and Soysal, M. (2017). "Time-dependent green vehicle routing problem with stochastic vehicle speeds: An approximate dynamic programming algorithm". Transportation Research Part D: Transport and Environment 54, pp. 82-98.

Koç, Çağrı, Bektaş, T., Jabali, O., and Laporte, G. (2016b). "Thirty years of heterogeneous vehicle routing". European Journal of $\mathrm{Op}$ erational Research 249, pp. 1-21.

Kopelowitz, A (1967). Computation of the kernels of simple games and the nucleolus of $N$-person games. Research Memorandum No. 31, Department of Mathematics, The Hebrew University of Jerusalem.

Li, S., Yu, Z., and Dong, M. (2015b). "Construct the stable vendor managed inventory partnership through a profit-sharing approach". International Journal of Systems Science 46, pp. 271283.

Littlechild, S. C. and Owen, G. (1973). "A simple expression for the Shapely value in a special case". Management Science 20, pp. 370372 .

Littlechild, S. C. and Thompson, G. F. (1977). "Aircraft landing fees: A game theory approach". The Bell Journal of Economics 8, pp. $186-204$. 
Lozano, S., Moreno, P., Adenso-Diaz, B., and Algaba, E. (2013). "Cooperative game theory approach to allocating benefits of horizontal cooperation". European Journal of Operational Research 229, pp. $444-452$.

Mahmoudzadeh, H., Purdie, T., and Chan, T. (2016). "Constraint generation methods for robust optimization in radiation therapy". Operations Research for Health Care 8, pp. 85-90.

Moen, O. (2014). "Co-distribution of municipal goods in Sweden Procurement from a new standpoint". Procedia - Social and Behavioral Sciences 125 . Ed. by E. Taniguchi and R. G. Thompson, pp. $484-495$.

Mrad, M. and Hidri, L. (2015). "Optimal consumed electric energy while sequencing vehicle trips in a personal rapid transit transportation system". Computers $\& \mathcal{G}$ Industrial Engineering 79, pp. 19.

Navarro, C., Roca-Riu, M., Furio, S., and Estrada, M. (2016). "Designing new models for energy efficiency in urban freight transport for smart cities and its application to the Spanish case". Transportation Research Procedia 12. Ed. by E. Taniguchi and R. G. Thompson, pp. 314-324.

Norde, H., Fragnelli, V., Garcia-Jurado, I., Patrone, F., and Tijs, S. (2002). "Balancedness of infrastructure cost games". European Journal of Operational Research 136, pp. 635-654.

Östlund, J. and Myhr, A. (2015). Transportarbete 1950-2014 (Swedish). www.trafa.se/sv/Statistik/Transportarbete/.

Özener, O. and Ergun, O. (2008). "Allocating costs in a collaborative transportation procurement network". Transportation Science 42, pp. $146-165$.

Puerto, J., Garcia-Jurado, I., and Fernandez, F. R. (2001). "On the core of a class of location games". Mathematical Methods of Operations Research 54, pp. 373-385.

Ropke, S. and Pisinger, D. (2006). "A unified heuristic for a large class of vehicle routing problems with backhauls". European Journal of Operational Research 171, pp. 750-775. 
Schliwa, G., Armitage, R., Aziz, S., Evans, J., and Rhoades, J. (2015). "Sustainable city logistics - Making cargo cycles viable for urban freight transport". Research in Transportation Business 83 Management 15 , pp. 50-57.

Schmeidler, D. (1969). "The nucleolus of a characteristic function game". SIAM Journal on Applied Mathematics 17, pp. 1163-1170.

Shapley, L. S. (1953). "A value for n-person games". In: Contributions to the theory of games II. Ed. by H. W. Kuhn and A. W. Tucker. Princeton University Press, Princeton, NJ, pp. 307-317.

Shapley, L. S. and Shubik, M. (1963). The core of an economy with nonconvex preferences. Tech. rep. Rand Corporation, Santa Monica, CA.

Shapley, L. S. and Shubik, M. (1966). "Quasi-cores in a monetary economy with nonconvex preferences". Econometrica 34, pp. 805827.

Stadtler, H., Kilger, C., and Meyr, H. (2015). Supply Chain Management and Advanced Planning: Concepts, Models, Software and Case Studies. Springer, Berlin.

Sudhölter, P. (1996). "The modified nucleolus as canonical representation of weighted majority games". Mathematics of Operations Research 21, pp. 734-756.

Talbi, E.-G. (2009). Metaheuristics: from Design to Implementation. Vol. 74. John Wiley \& Sons, Hoboken, NJ.

Taniguchi, E., Thompson, R. G., and Yamada, T. (1999). "Modelling City logistics." In: City logistics I. Ed. by R. G. Thompson and E. Taniguchi. Institute of Systems Science Research, pp. 3-37.

Taniguchi, E., G.Thompson, R., Yamada, T., and Duin, R. van (2001). City Logistics: Network Modelling and Intelligent Transport Systems. Pergamon, Amsterdam.

Taniguchi, E. (2014). "Concepts of city logistics for sustainable and liveable cities". Procedia - Social and Behavioral Sciences 151. Ed. by S. Iwan and R. G. Thompson, pp. 310-317.

Teo, J. S., Taniguchi, E., and Qureshi, A. G. (2012). "Evaluating city logistics measure in e-commerce with multiagent systems". 
Procedia - Social and Behavioral Sciences 39. Ed. by E. Taniguchi and R. G. Thompson, pp. 349-359.

Toth, P. and Vigo, D. (2014). Vehicle Routing: Problems, Methods, and Applications, Second Edition. MOS-SIAM Series on Optimization. Society for Industrial and Applied Mathematics, Philadelphia, PA.

Tragantalerngsak, S., Holt, J., and Rönnqvist, M. (2000). "An exact method for the two-echelon, single-source, capacitated facility location problem". European Journal of Operational Research 123, pp. $473-489$.

Tucker, A. (1950). A two-person dilemma. (unpublished notes).

Tucker, A. (1983). "The mathematics of Tucker: A sampler". The Two-Year College Mathematics Journal 14, pp. 228-232.

Vanovermeire, C. and Sörensen, K. (2014). "Measuring and rewarding flexibility in collaborative distribution, including twopartner coalitions". European Journal of Operational Research 239, pp. $157-165$.

Wangapisit, O., Taniguchi, E., Teo, J. S., and Qureshi, A. G. (2014). "Multi-agent systems modelling for evaluating joint delivery systems". Procedia - Social and Behavioral Sciences 125. Ed. by E. Taniguchi and R. G. Thompson, pp. 472-483.

Yang, D. and Odani, M. (2007). "An analysis on city freight cooperative transportation system using game theory." Journal of the Eastern Asia Society for Transportation Studies 7, pp. 989-1001.

Young, H. P., Okada, N., and Hashimoto, T. (1982). "Cost allocation in water resources development". Water Resources Research 18, pp. 463-475.

Young, H. P. (1985). Cost allocation : Methods, Principles, Applications. North-Holland, Amsterdam. 


\section{Abbreviations}

CDC City Distribution Center

CL City Logistics

EPM Equal Profit Method

$\triangle$ EPM $\Delta$ Equal Profit Method

EPML Equal Profit Method with Lexicography

LSP Logistics Service Provider

MP Monotonic Path

PRP Pollution Routing Problem

VMI Vendor Managed Inventory

VRP Vehicle Routing Problem 


\section{Papers}

The papers associated with this thesis have been removed for copyright reasons. For more details about these see:

http://urn.kb.se/resolve?urn=urn:nbn:se:liu:diva-153338 